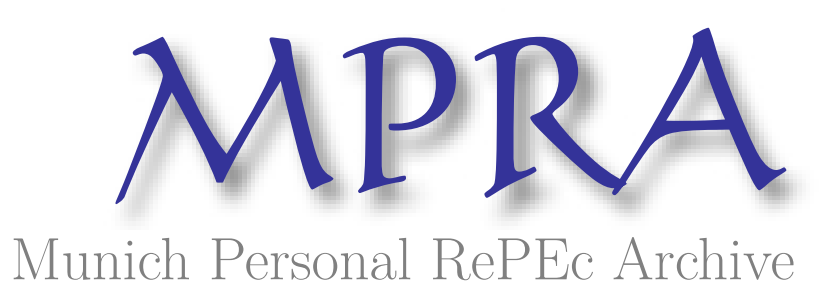

\title{
Sectoral Shift, Wealth Distribution, and Development
}

Yuki, Kazuhiro

Faculty of Economics, Kyoto University

30 May 2007

Online at https://mpra.ub.uni-muenchen.de/3384/

MPRA Paper No. 3384, posted 03 Jun 2007 UTC 


\title{
Sectoral Shift, Wealth Distribution, and Development
}

\author{
Kazuhiro Yuki* \\ forthcoming in Macroeconomic Dynamics
}

May 2007

\begin{abstract}
There are two phenomena widely observed when an economy departs from an underdeveloped state and starts rapid economic growth. One is the shift of production, employment, and consumption from the traditional sector to the modern sector, and the other is a large increase in educational levels of its population. The question is why some economies have succeeded in such structural change, but others do not. In order to examine the question, an OLG model that explicitly takes into account the sectoral shift and human capital accumulation as sources of development is constructed. It is shown that, for a successful structural change, an economy must start with a wealth distribution that gives rise to an adequate size of 'middle class'. Once the economy initiates the 'take-off', the sectoral shift and human capital growth continue until it reaches the steady state with high income and equal distribution. However, when the productivity of the traditional sector is low, irrespective of the initial distribution and the productivity of the modern sector, it fails in the sectoral shift and ends up in one of steady states with low income and high inequality. Thus, sufficient productivity of the traditional sector is a prerequisite for development.
\end{abstract}

JEL Classification Number: O11, O15.

Keywords: Human capital; Sectoral shift; Structural change; Wealth distribution

*Faculty of Economics, Kyoto University, Yoshida-hommachi, Sakyo-ku, Kyoto, 606-8501, Japan; Phone +81-75753-3532; E-mail yuki@econ.kyoto-u.ac.jp. I would like to thank Mark Bils for his continuous advice. Insightful comments and suggestions from two anonymous referees and an associate editor are gratefully appreciated. Valuable comments are also provided by Jeremy Greenwood, Per Krusell, Ananth Seshadri, and participants of presentations at the Kansai Macro Workshop and the University of Rochester. All remaining errors are mine. 


\section{Introduction}

There are two phenomena widely observed when an economy departs from an underdeveloped state and starts rapid economic growth. One is the shift of production, employment, and consumption from the traditional sector, such as traditional agriculture in rural areas and the urban informal sector, to the modern sector, such as modern manufacturing and commercial agriculture. The other is a large increase in educational levels of its population. ${ }^{1}$ Because the modern sector requires a larger pool of skilled labor, it is easy to see that these phenomena are related. The question is why some economies have succeeded in such 'structural change', but others do not. In order to tackle the question, particularly regarding contemporary developing economies, this paper constructs an OLG model that explicitly takes into account the sectoral change and human capital accumulation as sources of development.

It is shown that, for a successful structural change, an economy must start with a wealth distribution that gives rise to an adequate size of 'middle class'. Once the economy initiates the 'take-off', the sectoral shift and human capital growth continue until it reaches the steady state with high income and equal distribution. However, when the productivity of the traditional sector is low, irrespective of the initial distribution and the productivity of the modern sector, it fails in the sectoral shift and ends up in one of steady states with low income and high inequality. Thus, sufficient productivity of the traditional sector is a prerequisite for development.

The model economy has two sectors, traditional and modern, each producing a different kind of final good. The traditional sector hires unskilled labor and the modern sector employs skilled labor and physical capital to produce the goods. ${ }^{2}$ The market of the good produced in the traditional sector is closed domestically, ${ }^{3}$ while the market of the good produced in the modern sector, which is also used as a capital good, and the factor market of physical capital are open internationally. ${ }^{4}$

An agent in the economy lives for two periods. In childhood, she receives a transfer from the parent and allocates it between two investment opportunities, assets and education, in order to maximize future income. The investment in education is required to become a skilled worker and is individually profitable, although it is costly. The cost of education is the cost of hiring skilled workers as teachers. Since loan markets are nonexistent, tuition must be self-financed. Conse-

\footnotetext{
${ }^{1}$ Empirical facts on the sectoral shift are summarized in Syrquin (1988) and those on the education growth are surveyed in Schultz (1988).

${ }^{2}$ This assumption is made for simplicity. As long as the modern sector is more intensive in skilled labor, main results remain unchanged.

${ }^{3}$ The traditional sector corresponds to traditional agriculture and the urban informal sector in a real economy, which can be considered as nontradable sectors. See Section 2.3 for more detailed explanations.

${ }^{4}$ Perfect mobility of physical capital is assumed, mainly because it is more realistic than the other extreme of the closed market as a description of the situation of contemporary developing economies. By contrast, earlier theoretical attempts in development economics such as Lewis (1954) concern the problem of physical capital accumulation in industrialization of a low-income economy.
} 
quently, poor parents cannot make investments in educating their children despite its profitability, hence the investment decisions are affected by family income. In adulthood, the agent has a single child, earns income from work and assets, and spends on the consumption of the two goods and the intergenerational transfer.

The initial situation is that a large portion of the population is in the traditional sector and remains unskilled. Because there is little room left for growth in the traditional sector, in order to raise the standard of living significantly, the economy must accomplish the relocation of resources from the traditional sector to the modern sector. More individuals must be educated, but many of them are credit constrained and cannot make optimal investments. Under what conditions can such economy succeed?

A part of the answer is that, as mentioned earlier, the economy must start with an initial wealth distribution that gives rise to an adequate size of 'middle class' (those who have enough wealth to take education). The requirement for the 'take-off' is that a portion of unskilled workers accumulates wealth sufficient for their children to take education and get skilled jobs in the modern sector. The source of labor income of unskilled workers is sales of the good produced in the traditional sector. Its relative price in turn depends positively on the number of skilled workers and aggregate assets: a higher number of skilled workers implies higher demand and lower supply of the good, and greater wealth leads to the higher demand. Thus, for the sectoral shift to start, the size of 'middle class' and aggregate assets must be above certain levels.

If the initial wealth distribution is such that a relatively large portion of the population has access to education and becomes skilled workers, the price of the traditional good and thus the unskilled wage are high. If the price level is above the critical level, a richer portion of unskilled workers can send their children to school and the sectoral shift starts immediately. Even when the initial price level is not high enough for the shift due to modest aggregate assets, the relatively large pool of skilled workers makes rapid wealth accumulation possible, hence the price level rises to the critical level at some point and the economy 'take offs'. Once the sectoral change starts, it continues autonomously. An increase in the number of skilled workers raises the demand for the good, reduces its supply, and stimulates asset accumulation. All contribute to further increases in the price of the good and the unskilled wage. This allows children of less affluent unskilled workers to access education and thus increases the number of skilled workers further, lifting the price and the unskilled wage even more. As long as the skilled wage (net of the cost of education) is higher than the unskilled wage, this process continues. In the long run, the economy reaches the state in which the return from education is equated with that from assets, thus equal opportunity is 
attained..$^{5}$

In contrast, if the economy starts with a relatively small size of 'middle class', the number of skilled workers is limited, hence the price of the traditional good is low. Children of unskilled workers are not able to access education financially and the number of skilled workers does not increase. If initial wealth is low, the relative price increases over time through wealth accumulation but never reaches the critical level for the sectoral shift. Because skilled labor remains scarce, even in the long run, inequality between skilled and unskilled workers does not disappear and the investment choices are affected by family income.

However, a 'good' initial wealth distribution is not sufficient for the success when there is the sectoral shift of consumption, i.e. preferences are such that the income (and price) elasticity of demand for the traditional good is less than one, while those for the modern good and the transfer are more than one. If the productivity of the traditional sector is low, the economy ends up in a steady state with persistent inequality irrespective of the initial distribution and the productivity of the modern sector. Thus, sufficient productivity of the traditional sector is a prerequisite for the successful development. Because the price elasticity of the traditional good is less than one, when the productivity of the sector is lower, its price becomes higher more than proportionately and the unskilled wage rises. The resultant lower return from education implies that the economy can sustain fewer skilled workers and lower aggregate assets. If the productivity is below a certain level, the sustainable skilled labor and aggregate assets become smaller than the levels required for the 'take-off' and thus the sectoral shift does not start.

The argument so far has assumed time-invariant productivities for the both sectors. The above results are not largely affected by the introduction of productivity growth, as long as the cost of education increases with the skilled wage. An economy starting with an unproductive traditional sector is still unlikely to succeed in the structural change, irrespective of initial wealth distribution and modern sector productivity. A new possibility is that an economy initially experiencing sectoral shift may end up in a steady state with moderate income and high inequality, if wealth is relatively concentrated in the rich.

The paper has several policy implications. The most important one would be that, when the productivity of the traditional sector is low, policies enhancing the productivity and those correcting wealth inequality (or lowering the private cost of education) must be conducted together. However, the former policies should be executed with great care, because they have negative effects on the unskilled wage, transfers by unskilled workers, and thus the upward mobility of their descendants.

\footnotetext{
${ }^{5}$ Larson and Mundlak (1997) finds that the ratio of average labor productivity of agricultural workers to that of non-agricultural workers converges to one as an economy develops. Some evidence indicates that the size of the informal sector and the wage differential between the informal and formal sectors decrease with development through human capital accumulation (Marcouiller et al., 1997; Ranis and Stewart, 1999).
} 
The priority between the two kinds of policies depends on the productivity level and the stage of development.

Empirical findings largely support the model's implications. The first point of the paper, the importance of initial wealth distribution, especially the initial size of 'middle class', in economic development, through its effect on human capital accumulation, has been backed by many studies. Using panel data of wider coverage and of higher quality than those of earlier studies, Deininger and Squire (1998) and Deininger and Olinto (2000) discover that an economy's growth rate is affected negatively by initial land inequality (a proxy for initial asset inequality) and positively by its mean years of schooling per working person (a proxy for human capital). ${ }^{6}$ Further, they find that the average educational attainment is negatively affected by initial land inequality, the effect of human capital is greater in a lower-income economy, and initial land and income inequality affect negatively the income growth of the poor, but not of the rich. Using cross-sectional data from the 1960s to the 1990s, Easterly (2001) finds that a larger size of 'middle class', measured as the share of income held by the second through fourth quintiles of the distribution, is associated with more education, especially at the secondary level, higher income, and higher growth.

The second point of the paper, sufficient productivity in the traditional sector as a precondition for a successful sectoral shift, has not been formally tested, although there are several findings indirectly supporting the claim. Bairoch (1975) points out the large gap (about 45 percent) in agricultural productivity on average between European countries at the onset of their industrial revolutions and Africa and Asia in the 1960s. Further, Hayami and Ruttan (1985) finds a close positive association between overall output growth and agricultural productivity growth for SubSaharan African nations.

This paper is mainly related to two strands of literature. One is the literature that investigates mechanisms and consequences of structural change. Matsuyama (1992) investigates the role of agricultural productivity in economic development using a two-sector endogenous growth model and shows how the openness of markets affects the relationship between productivity and growth. Using a neoclassical growth model with multiple consumption goods and non-homothetic preferences, Echevarria (1997) numerically shows that uneven productivity growth among sectors can lead to different aggregate growth rates at different stages of development. Kongsamut et al. (2001) and Ngai and Pissarides (2004) study multi-sector growth models related to the one investigated by Echevarria and derive conditions for structural change and balanced growth. Laitner (2000) explains how an economy's measured average propensity to save rises in the course of industrialization by focusing on the increasing importance of reproducible capital relative to land. Wang and Xie (2004)

\footnotetext{
${ }^{6}$ Unless aggregate wealth accumulation is very low, a more equal wealth distribution implies that a larger proportion of individuals can afford education.
} 
examine factors affecting the activation of a modern industry based on a static two-sector model with non-homothetic preferences and uncompensated spillovers in the IRS modern sector. These papers as well as the present paper focus on sectoral shifts in the modern growth era. By contrast, Hansen and Prescott (2002) are concerned with the transition from stagnation to modern economic growth during past several hundred years in contemporary developed economies. Based on a two-sector OLG model, they argue that the adoption of less land-intensive production technology induced by productivity growth is the main driving force.

The other is the large literature that investigates the interplay between income distribution and growth theoretically, which includes Banerjee and Newman (1993), Galor and Zeira (1993), Ljungqvist (1993), Persson and Tabellini (1994), Benabou (1996a, 1996b), Benhabib and Rustichini (1996), Aghion and Bolton (1997), Lloyd-Ellis and Bernhardt (2000), and Galor and Moav (2004).

Most closely related is the paper by Galor and Zeira, which shows how credit constraint and lumpy investment in human capital can create the interaction between initial distribution and longrun output and inequality. They consider an economy composed of two sectors that are similar in production technologies to the present paper but both produce the same tradable good. (Thus, the sectoral shift of consumption is not considered.) In a version of the model with land as a factor of production of the traditional sector, ${ }^{7}$ the unskilled wage and thus the upward mobility of the poor depend on wealth distribution and the skilled wage, as in this paper. (They depend on aggregate assets too in the present model.) However, the mechanism is different. In the Galor and Zeira model, what gives rise to the dependency is a decreasing marginal return to labor in the traditional sector and the credit constraint that individuals can borrow to finance education but at a higher rate than the lending rate, which makes the number of borrowers and thus the number of skilled workers affected by the return to education. In the present model, the dependency comes from the endogenous relative price of the traditional good that reflects both demand and supply factors. Further, with the sectoral shift of consumption, resources available to skilled workers also depend on the relative price. In terms of policy implications, the most contrasting would be effects of policies improving access to education through transfers to the poor. In their model, irrespective of the productivity level of the traditional sector, such policies are sufficient for an economy to escape from the state of low output and high inequality. By contrast, in the present model with the sectoral shift of consumption, when the productivity is low, such policies must be implemented together with the productivity-enhancing policies.

Galor and Moav construct a one-sector OLG model related to that of Galor and Zeira, in order to explain the transition of the main engine of growth from physical capital accumulation (in early

\footnotetext{
${ }^{7}$ Footnotes 11, 19, and 26 discuss a modified model where land is included as in the Galor and Zeira model. Qualitative results are not affected by the modification.
} 
stages of the Industrial Revolution) to human capital accumulation (in the modern growth era). Further, they show that the effect of inequality on growth turns from positive to negative with the replacement of the prime source of growth.

The paper is organized as follows. Section 2 presents the model without the sectoral shift of consumption. Section 3 derives and analyzes the model's dynamics and Section 4 presents and interprets the results from the basic model. In Section 5, the sectoral shift of consumption is introduced into the model and its effects on the results are examined. Further, policy implications of the model are discussed. Section 6 concludes the paper.

\section{Model}

\subsection{Individual decisions}

Time is discrete and starts from 0 . There is no uncertainty. The economy is composed of a continuum of individuals who live for two periods.

\subsubsection{Investment decisions}

In childhood, an individual receives a transfer from her parent and allocates it for two investment options, assets and education, in order to maximize future income. ${ }^{8}$ Education, which would correspond roughly to secondary education in actual developing economies, is required to become a skilled worker and enjoy higher earnings in adulthood. The investment is a discrete choice, i.e. takes education or not, and incurs a fixed cost. Consider an individual who was born into lineage $i$ in period $t-1$, whose generation is called generation $t$. Her education costs $e_{t}$, and its gross return is $w_{H, t}-w_{L, t}$ in the next period, where $w_{H, t}$ and $w_{L, t}$ are skilled and unskilled wages in period $t$, respectively. Assume that the education cost is the cost of hiring current skilled workers as teachers and it is proportional to $w_{H, t-1}$, i.e. $e_{t}=s_{e} w_{H, t-1}$, where $s_{e}$ is a constant. ${ }^{9}$ The investment must be self-financed because loan markets for such investment are not available: the child's future income is not a valid collateral in the financially underdeveloped economy. The other option, the investment in assets, is a continuous choice, and brings a gross rate of return of $1+r_{t}$. It is easily shown that, in an equilibrium, the return from the educational investment becomes at least as high as the return from the investment in assets, i.e. $w_{H, t}-w_{L, t} \geq\left(1+r_{t}\right) e_{t}$.

\footnotetext{
${ }^{8}$ Alternatively, one can suppose that the investment decisions are carried out by the parent in order to maximize the child's future income. Note that the transfer in the model corresponds to total intergenerational transfers including bequests, education, and other inter-vivos transfers in real life. The decision that the child (or the parent) has to make is the allocation of the whole transfers between education and assets.

${ }^{9}$ Kendrick (1976) finds that teacher and student time constitute about $90 \%$ of all costs of education. Further, World Bank (1983) notes that about $95 \%$ of current expenses in primary school systems of low income countries are teacher salaries. In addition to direct costs of education, foregone earnings are important costs particularly in a low income economy. Results are not affected by the inclusion of foregone earnings to the cost.
} 
Suppose that the individual has received $b_{t}^{i}$ units of income as a transfer from the parent. If the return from the investment in education is strictly higher than that from the investment in assets, optimal investment choices of assets $a_{t}^{i}$ and education $e_{t}^{i}$ are given by the following equations: ${ }^{10}$

$$
\begin{array}{r}
\text { If } \quad b_{t}^{i}<e_{t}, \quad a_{t}^{i}=b_{t}^{i}, \quad e_{t}^{i}=0, \\
\text { and if } \quad b_{t}^{i} \geq e_{t}, \quad a_{t}^{i}=b_{t}^{i}-e_{t}, e_{t}^{i}=e_{t} .
\end{array}
$$

Since innate abilities of individuals are identical, transfers solely determine the investment and resulting occupational choices.

\subsubsection{Consumption and transfer decisions}

An adult individual, who is either a skilled or unskilled worker depending on the human capital investment in the previous period, obtains income from assets and labor supply and spends the income on consumption and transfer to her child. Each adult is assumed to have a single child. There are two different consumption goods, good L and good H. Characteristics of the goods are described later in this section. Assume that an adult individual of lineage $i$ in generation $t$ has the following utility function:

$$
U_{t}^{i}=\left(c_{L, t}^{i}\right)^{\gamma_{l}}\left(c_{H, t}^{i}\right)^{\gamma_{h}}\left(b_{t+1}^{i}\right)^{1-\gamma_{l}-\gamma_{h}},
$$

where $c_{L, t}^{i}$ and $c_{H, t}^{i}$ are her consumption of good $\mathrm{L}$ and good $\mathrm{H}$, respectively and $b_{t+1}^{i}$ is the transfer to the child (generation $t+1$ ). Denote the relative price of good L to good $\mathrm{H}$ in period $t$ by $P_{t}$. Then, the budget constraint is ( $w_{t}^{i}$ is her earnings)

$$
P_{t} c_{L, t}^{i}+c_{H, t}^{i}+b_{t+1}^{i}=w_{t}^{i}+\left(1+r_{t}\right) a_{t}^{i}
$$

Maximization of (3) subject to (4) gives the following consumption and transfer rules:

$$
\begin{aligned}
P_{t} c_{L, t}^{i} & =\gamma_{l}\left[w_{t}^{i}+\left(1+r_{t}\right) a_{t}^{i}\right], \\
c_{H, t}^{i} & =\gamma_{h}\left[w_{t}^{i}+\left(1+r_{t}\right) a_{t}^{i}\right], \\
\text { and } \quad b_{t+1}^{i} & =\left(1-\gamma_{l}-\gamma_{h}\right)\left[w_{t}^{i}+\left(1+r_{t}\right) a_{t}^{i}\right] .
\end{aligned}
$$

\footnotetext{
${ }^{10}$ Actually, the relative return from education is determined as the result of people's investment decisions, since it depends on the numbers of skilled and unskilled workers in the economy. More formal analysis of the investment decision is described in the next section.
} 


\subsubsection{Generational structure}

At the beginning of period $t+1$, current adults pass away, current children become adults, and new children are born into the economy. Since each adult has one child, the population is constant over time. The population of each generation is normalized to be one.

\section{$2.2 \quad$ Production structure}

There are two production sectors, sector L (the traditional sector) and sector $\mathrm{H}$ (the modern sector). Sector L employs unskilled workers to produce good L, and sector $\mathrm{H}$ employs skilled workers and physical capital to produce good H. Good H is used for investment in physical capital as well.

The production functions of the two sectors are given as follows:

$$
\begin{aligned}
\text { Sector L: } & Y_{L, t}=A_{L, t} L_{t}, \\
\text { Sector H: } & Y_{H, t}=A_{H, t}\left(H_{H, t}\right)^{\alpha}\left(K_{t}\right)^{1-\alpha}, \quad 0<\alpha<1 .
\end{aligned}
$$

In the above expressions, $Y_{L, t}$ and $Y_{H, t}$ are outputs of good $\mathrm{L}$ and good $\mathrm{H}$, respectively, $A_{L, t}$ and $A_{H, t}$ are productivity levels of the respective sectors, $L_{t}$ is the number of unskilled workers, $H_{H, t}$ is the number of skilled workers in sector $\mathrm{H}$ (the rest of skilled workers are employed in the education sector), and $K_{t}$ denotes physical capital. ${ }^{11}$ To focus on main mechanics of the model, in most parts of the paper, the productivities $A_{L, t}$ and $A_{H, t}$ are assumed to be constant over time, i.e. $A_{L, t}=A_{L}$ and $A_{H, t}=A_{H}$. As described later, main results remain intact with the introduction of exogenous productivity growth.

The assumptions that unskilled workers are employed only in sector L, and skilled workers and physical capital are employed only in sector $\mathrm{H}$ are made for simplicity. Provided that the former sector is more intensive in unskilled labor and the latter sector is more intensive in skilled labor, the outcome from the model remains largely unchanged.

\subsection{Market structure and determination of prices}

Suppose that the markets for good L and for labor are closed domestically, while good H and physical capital are freely mobile internationally. The assumptions on the final goods would be better understood by associating them with goods in an actual economy.

The first interpretation is that good $\mathrm{L}$ is agricultural goods produced with traditional technology, and good $\mathrm{H}$ is manufacturing and agricultural goods produced with modern technology. Traditional

\footnotetext{
${ }^{11}$ As mentioned in the introduction and explained in the next subsection, sector L corresponds to the urban informal sector as well as traditional agriculture in a real economy, hence land is not included in the production function. If land is a factor of production, the production function may be formulated as: $Y_{L, t}=A_{L, t}\left(L_{t}\right)^{\beta}(Z)^{1-\beta}, 0<\beta<1$, where $Z$ is the fixed amount of land. Effects of the inclusion of land on results are mentioned in footnotes 19 and 26 .
} 
agriculture is engaged on a small scale by families located in rural areas and produces agricultural goods largely for basic needs. Because its productivity is low and transportation costs and traders' margins are high due to poor infrastructure and distribution system, ${ }^{12}$ it supplies the product mostly for domestic markets. By contrast, modern manufacturing and commercial agriculture compete more directly with foreign suppliers.

The second interpretation is that good L is non-tradable services and manufacturing goods produced with technologies intensive in unskilled labor, such as petty trading, personal services, and repairing services, and good $\mathrm{H}$ is manufacturing goods produced with technologies intensive in skilled labor and physical capital. That is, sector L and sector H may be considered as the informal and formal sectors of an urban economy, respectively. There is an evidence showing that the size of the urban informal sector is substantial in most developing countries, in many cases accounting for over half of the urban workforce (Ranis and Stewart, 1999). ${ }^{13}$

Perfect mobility of physical capital is assumed, because it is more realistic than the other extreme of the closed market as a description of the situation of contemporary developing economies, and it enables the paper to focus on human capital accumulation rather than physical capital accumulation as the prime source of development.

From the assumptions, the interest rate is fixed at the world interest rate $r_{t}=r$, which is assumed to be time-invariant, and the skilled wage $w_{H}$ is given by the following equation. ${ }^{14}$

$$
w_{H}=\alpha\left(A_{H}\right)^{\frac{1}{\alpha}}\left(\frac{1-\alpha}{r}\right)^{\frac{1}{\alpha}-1} .
$$

The wage rate is exogenous and constant over time. The wage of unskilled workers equals

$$
w_{L, t}=P_{t} A_{L},
$$

hence it depends on the relative price of good $\mathrm{L}$ to good $\mathrm{H}, P_{t}$.

\footnotetext{
${ }^{12}$ See, for example, Minten and Kyle (1999) for an evidence from former Zaire.

${ }^{13}$ Of course, in a real economy, there exist skill-intensive sectors that supply nontradable services and goods. However, in lower developing countries, most of skill-intensive nontradables are public services, health services, and education, where service prices and wages are determined more by institutional factors than by market conditions, while nontradable sectors influenced more directly by market factors, such as financial services and consulting services, are limited in size. By comparison, as explained in the main text, traditional agriculture and the urban informal sector are important parts of unskilled-intensive sectors in developing countries. Hence, the assumption on the tradability of the two final goods would be justified. Note that, as mentioned in the previous subsection, the assumption that sector $\mathrm{H}$ employs only skilled labor and physical capital and sector L employs only unskilled workers can be relaxed without affecting main results largely.

${ }^{14}$ From the first-order conditions of the profit-maximizing problem of the firm in sector $\mathrm{H}$,

$$
\begin{aligned}
r_{t} & =(1-\alpha) A_{H}\left(\frac{H_{H, t}}{K_{t}}\right)^{\alpha}, \\
\text { and } w_{H, t} & =\alpha A_{H}\left(\frac{K_{t}}{H_{H, t}}\right)^{1-\alpha} .
\end{aligned}
$$
}

Solving the first equation for $\frac{H_{H, t}}{K_{t}}$, substituting it into the second equation, and setting $r_{t}=r$ gives (10). 
The relative price is determined by the market-clearing condition of good L. The demand for good $\mathrm{L}$ is the total consumption of the good by the adult population, which is the sum of individual consumption (5) over the population. So the market-clearing condition becomes

$$
P_{t} A_{L} L_{t}=\gamma_{l}\left[w_{L, t} L_{t}+w_{H} H_{t}+(1+r) \sum_{i} a_{t}^{i}\right] .
$$

In the above equation, $H_{t}$ is the total number of skilled workers, which is the sum of $H_{H, t}$ and $H_{E, t}$ (the number of skilled workers in the education sector), and $\sum_{i} a_{t}^{i}$ is aggregate assets. Note that, due to free international capital mobility, it could be the case that a large portion of the assets are invested abroad, if there do not exist enough investment opportunities within the economy. By substituting (11) and $H_{t}+L_{t}=1$ into the above equation and solving for $P_{t}$, the relative price of good L is given as follows:

$$
P_{t}=\frac{\gamma_{l}}{1-\gamma_{l}} \frac{w_{H} H_{t}+(1+r) \sum_{i} a_{t}^{i}}{A_{L}\left(1-H_{t}\right)}
$$

The relative price $P_{t}$ increases with the number of skilled workers $H_{t}$ and aggregate assets. Larger $H_{t}$ and $\sum_{i} a_{t}^{i}$ imply greater total income and higher demand of good $\mathrm{L}$, and larger $H_{t}$ (smaller $L_{t}$ ) implies lower supply of the good, hence higher $P_{t}$. Since $w_{L, t}=P_{t} A_{L}$, the unskilled wage is also increasing in $H_{t}$ and $\sum_{i} a_{t}^{i}$.

For analyses in later sections, it is convenient to express the relative price as a function of $H_{t}$ and aggregate intergenerational transfers, $B_{t}$, by substituting $\sum_{i} a_{t}^{i}=B_{t}-e H_{t}$ into the above equation $(13):^{15}$

$$
P_{t}=\frac{\gamma_{l}}{1-\gamma_{l}} \frac{\left[w_{H}-(1+r) e\right] H_{t}+(1+r) B_{t}}{A_{L}\left(1-H_{t}\right)}
$$

The relative price and the unskilled wage are increasing in both $H_{t}$ and $B_{t}$. To express the dependency of $P_{t}$ and $w_{L, t}$ on $H_{t}$ and $B_{t}$, they are denoted as $P\left(H_{t}, B_{t}\right)$ and $w_{L}\left(H_{t}, B_{t}\right)$, respectively.

The education sector employs skilled workers as teachers to provide educational services to students. Since tuition equals $e$ and the number of students is $H_{t+1}$ in period $t$, the market-clearing condition is

$$
\begin{aligned}
w_{H} H_{E, t} & =e H_{t+1}, \\
\text { or } \quad H_{E, t} & =s_{e} H_{t+1} .
\end{aligned}
$$

The above equation shows that the constant $s_{e}$ represents the number of teachers needed to teach one student. It is assumed that $s_{e}<1$ is low enough that the above condition is satisfied without

\footnotetext{
${ }^{15}$ The relation $\sum_{i} a_{t}^{i}=B_{t}-e H_{t}$ is satisfied because current skilled workers have spent $e$ on education out of their received transfers in the previous period. Note that the cost of education is time-invariant because the skilled wage $w_{H}$ is constant over time.
} 
rationing: otherwise, not all children who have enough wealth to pay tuition could receive education because of a shortage of teachers.

\section{Dynamics}

In the model economy, individuals live only for two periods and participate in each market for one period alone: each market consists of individuals of a single generation each period. Hence, the model can be considered as a sequence of static economies.

What connects these static economies across periods are intergenerational transfers. Because of the credit constraint, transfers directly affect individuals' investment and occupational choices, and consequently consumption and transfer decisions. Further, the distribution of transfers over the population determines the proportion of individuals who can afford to take education, and thus it affects the relative return from education and investment decisions. Hence, in general, the time evolution of the distribution of transfers must be examined in order to understand how the economy's structure, such as production and employment shares of each sector, total output, and wage and asset distributions, change over time.

This section first derives the dynamic equation linking the current period's transfer to the next period's transfer within a lineage (individual dynamics). The dynamics depend on the time evolution of two aggregate variables that in turn are determined by the dynamics of the distribution of transfers. However, it turns out that, sufficient information for obtaining the model's implications is the directions of motion of the aggregate variables, which can be derived without knowledge on the distributional dynamics. Thus the dynamics of the two aggregate variables are examined next. Although the two dynamics interact, for exposition, initially the dynamics of each variable are analyzed fixing the other, then the both dynamics are analyzed together by introducing a phase diagram.

\subsection{Individual dynamics}

Consider an individual born into lineage $i$ in period $t-1$, who belongs to generation $t$. She allocates transfer $b_{t}^{i}$ between investments in assets $a_{t}^{i}$ and in education $e_{t}^{i}$ so as to maximize future income. If the transfer is less than the cost of education, i.e. $b_{t}^{i}<e$, the transfer is spent only on assets and she becomes an unskilled worker, as described earlier. By contrast, if $b_{t}^{i} \geq e$ is satisfied, the investment decision is more complicated. Because investment decisions of others affect $w_{L}\left(H_{t}, B_{t}\right)$ and the relative return from education, she has to take into account their actions. The key variable affecting the decision is the fraction of individuals with $b_{t}^{i} \geq e, F_{t}$. In short, when only a small number of individuals can afford education, all of them take education and become skilled, whereas, 
when many individuals have access to education, some of them become unskilled workers and the wages (net of the cost of education) are equalized.

\subsubsection{Unequal opportunity case}

When the proportion of individuals who can afford to take education is small, the return from education is higher than the return from assets, even if all of them take education, i.e. $w_{H}-(1+r) e>$ $w_{L}\left(F_{t}, B_{t}\right)$. In this case, the individual allocates the transfer in the following manner:

$$
\begin{array}{r}
\text { If } \quad b_{t}^{i}<e, \quad a_{t}^{i}=b_{t}^{i}, \quad e_{t}^{i}=0, \\
\text { and if } \quad b_{t}^{i} \geq e, \quad a_{t}^{i}=b_{t}^{i}-e, e_{t}^{i}=e .
\end{array}
$$

Thus, all young individuals who are financially eligible for education become skilled workers, i.e. $H_{t}=F_{t}$. Since transfers from parents constrain access to the profitable investment opportunity, this case is called the unequal opportunity case.

In the next period, the individual, given asset $a_{t}^{i}$ and acquired ability (skilled or unskilled), determines the amount of transfer to the child $b_{t+1}^{i}$ according to (7). By substituting the above investment rules into (7), the dynamic equation linking the received transfer $b_{t}^{i}$ to the transfer given to the next generation $b_{t+1}^{i}$ is derived.

If she is a skilled worker, i.e. $b_{t}^{i} \geq e$, the equation takes the following form:

$$
b_{t+1}^{i}=b_{s}\left(b_{t}^{i}\right) \equiv\left(1-\gamma_{l}-\gamma_{h}\right)\left\{w_{H}+(1+r)\left(b_{t}^{i}-e\right)\right\} .
$$

The assumption $\left(1-\gamma_{l}-\gamma_{h}\right)(1+r)<1$ is made so that the fixed point of the equation $\left(b_{s}\right)^{*} \equiv$ $\frac{1-\gamma_{l}-\gamma_{h}}{1-\left(1-\gamma_{l}-\gamma_{h}\right)(1+r)}\left[w_{H}-(1+r) e\right]$ is stable.

For an unskilled worker, i.e. $b_{t}^{i}<e$, the equation becomes

$$
\begin{aligned}
b_{t+1}^{i}=b_{u}\left(b_{t}^{i} ; F_{t}, B_{t}\right) & \equiv\left(1-\gamma_{l}-\gamma_{h}\right)\left\{w_{L}\left(F_{t}, B_{t}\right)+(1+r) b_{t}^{i}\right\} \\
\text { where } \quad w_{L}\left(F_{t}, B_{t}\right) & =\frac{\gamma_{l}}{1-\gamma_{l}} \frac{\left[w_{H}-(1+r) e\right] F_{t}+(1+r) B_{t}}{\left(1-F_{t}\right)} .
\end{aligned}
$$

The dynamic equation for an unskilled worker does depend on the aggregate variables $H_{t}=F_{t}$ and $B_{t}$, because they affect the relative price of good $\mathrm{L}$ and thus the unskilled wage. The fixed point for given $F_{t}$ and $B_{t}$ is denoted by $b_{u}^{*}\left(F_{t}, B_{t}\right) \equiv \frac{1-\gamma_{l}-\gamma_{h}}{1-\left(1-\gamma_{l}-\gamma_{h}\right)(1+r)} w_{L}\left(F_{t}, B_{t}\right) .{ }^{16}$

The dynamics of a current skilled worker, $b_{t+1}^{i}=b_{s}\left(b_{t}^{i}\right)$ and of a current unskilled worker, $b_{t+1}^{i}=$ $b_{u}\left(b_{t}^{i} ; F_{t}, B_{t}\right)$, for given $F_{t}$ and $B_{t}$ are depicted in Figure $1 .{ }^{17}$ As long as $w_{H}-(1+r) e>w_{L}\left(F_{t}, B_{t}\right)$

\footnotetext{
${ }^{16}$ This may not be the long-run transfer level of her lineage, because her descendants may become skilled workers and $F_{t}$ and $B_{t}$ could change over time. One might think that this fixed point does not have any economic importance, but it turns out that the level of $b_{u}^{*}\left(F_{t}, B_{t}\right)$ is crucial for aggregate dynamics (detailed later).

${ }^{17}$ To be more accurate, $b_{t+1}^{i}=b_{s}\left(b_{t}^{i}\right)$ is defined only for $b_{t}^{i} \geq e$ and $b_{t+1}^{i}=b_{u}\left(b_{t}^{i}\right)$ is only for $b_{t}^{i}<e$. However,
} 


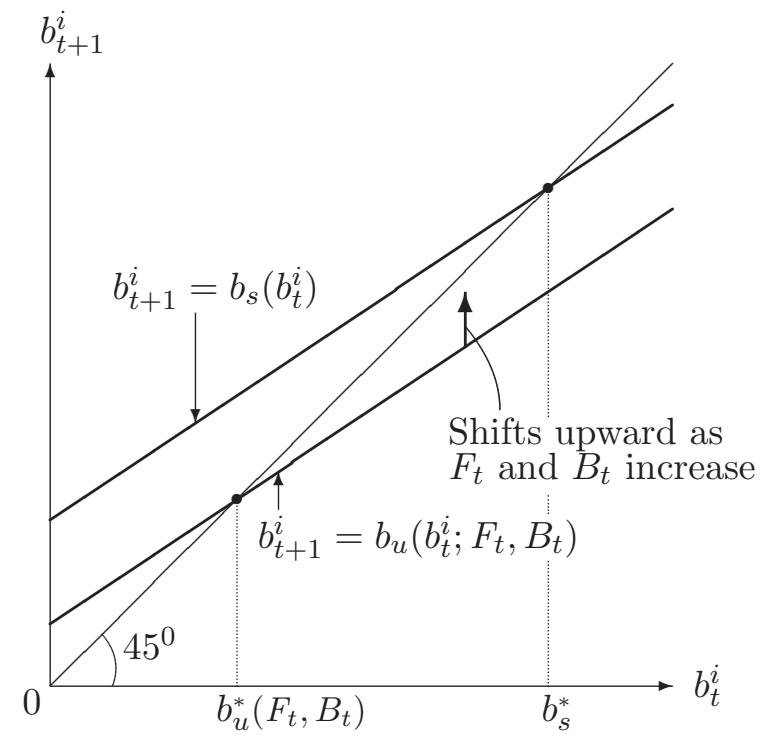

Figure 1: Individual dynamics of intergenerational transfers

is satisfied, $b_{t+1}^{i}=b_{u}\left(b_{t}^{i} ; F_{t}, B_{t}\right)$ is located below $b_{t+1}^{i}=b_{s}\left(b_{t}^{i}\right)$, but it shifts upward with increases in $F_{t}$ and $B_{t}$.

\subsubsection{Equal opportunity case}

Next, consider the case in which many individuals can afford education so that the return from education fails to be higher than the return from assets, if all of them invest in education, i.e. $w_{H}-(1+r) e \leq w_{L}\left(F_{t}, B_{t}\right)$. In this situation, the number of skilled workers $H_{t}$ is determined at the point where the two returns are equated, i.e. $w_{H}-(1+r) e=w_{L}\left(H_{t}, B_{t}\right)$. Now not all of financially eligible individuals take education and become skilled workers, i.e. $H_{t} \leq F_{t}$. Since the return from the investments does not depend on transfers from parents, this case is named the equal opportunity case. Dynamics of transfers of the both types of workers are described by $b_{t+1}^{i}=b_{s}\left(b_{t}^{i}\right)$, (19). In Figure 1 , this is the situation where $P\left(H_{t}, B_{t}\right)$ is high enough that $b_{t+1}^{i}=b_{u}\left(b_{t}^{i} ; H_{t}, B_{t}\right)$ coincides with $b_{t+1}^{i}=b_{s}\left(b_{t}^{i}\right)$.

\subsubsection{Dividing line}

The economy belongs to either of the two cases depending on $F_{t}$ and $B_{t}$. The combination of $F_{t}$ and $B_{t}$ satisfying $w_{H}-(1+r) e=w_{L}\left(F_{t}, B_{t}\right)$ is the dividing line, which is obtained by substituting $P_{t}=\left[w_{H}-(1+r) e\right] / A_{L}, \sum_{i} a_{t}^{i}=B_{t}-e H_{t}$, and $H_{t}=F_{t}$ into (13) and solving for $F_{t}$ :

$$
F_{t}=H^{e}\left(B_{t}\right) \equiv\left(1-\gamma_{l}\right)-\frac{\gamma_{l}(1+r) B_{t}}{w_{H}-(1+r) e} .
$$

since the location of $e$ relative to $b_{u}^{*}\left(F_{t}, B_{t}\right)$ depends on $F_{t}$ and $B_{t}, e$ is not shown in the figure. Precise dynamics of individual transfers are illustrated later (Figures 2 and 3 ). 
The unequal opportunity case corresponds to $F_{t}<H^{e}\left(B_{t}\right)$, while the equal opportunity case amounts to $F_{t} \geq H^{e}\left(B_{t}\right)=H_{t}$.

\subsection{Aggregate dynamics}

What has become clear now is that the individual dynamics and the evolution of wages and the relative price depend on the dynamics of two aggregate variables, aggregate transfers $B_{t}$ and the fraction of individuals satisfying $b_{t}^{i} \geq e, F_{t}$. Given the initial distribution of transfers, $B_{0}$ and $F_{0}$ are determined directly, while levels of the aggregate variables in subsequent periods are determined by the dynamics of the distribution of transfers. However, as mentioned earlier, information on the direction of motion of the aggregate variables, which can be derived without knowledge on the distributioal dynamics, is enough to obtain main implications of the model. Thus, this subsection analyzes the dynamics of $B_{t}$ and $F_{t}$ qualitatively. For exposition, each of them is examined separately fixing the other variable first, then their interaction is taken into account at the end.

\subsubsection{Dynamics of aggregate transfers}

First, the dynamics of aggregate intergenerational transfers $B_{t}$ are examined for given $F_{t}$. Consider the unequal opportunity case, i.e. $F_{t}<H^{e}\left(B_{t}\right)$. As seen in the previous subsection, $w_{H}-(1+r) e>$ $w_{L}\left(H_{t}, B_{t}\right)$ and $H_{t}=F_{t}$ hold in this case. The dynamic equation of aggregate transfers is

$$
B_{t+1}=B\left(F_{t}, B_{t}\right) \equiv \frac{1-\gamma_{l}-\gamma_{h}}{1-\gamma_{l}}\left\{\left[w_{H}-(1+r) e\right] F_{t}+(1+r) B_{t}\right\},
$$

which is derived by aggregating individual dynamics of skilled (19) and of unskilled workers (20) over the population and substituting $H_{t}=F_{t}$. The assumption $\frac{1-\gamma_{l}-\gamma_{h}}{1-\gamma_{l}}(1+r)<1$ is made so that there exists a fixed point that is globally stable for given $F_{t}$, where the fixed point $B^{*}\left(F_{t}\right)$ equals

$$
B^{*}\left(F_{t}\right) \equiv \frac{1}{1-\frac{1-\gamma_{l}-\gamma_{h}}{1-\gamma_{l}}(1+r)} \frac{1-\gamma_{l}-\gamma_{h}}{1-\gamma_{l}}\left[w_{H}-(1+r) e\right] F_{t} .
$$

Alternatively, in the equal opportunity case $\left(F_{t} \geq H^{e}\left(B_{t}\right)\right), w_{H}-(1+r) e=w_{L}\left(H_{t}, B_{t}\right)$, i.e. $H_{t}=H^{e}\left(B_{t}\right)$, holds. In this case, the dynamic equation is obtained by substituting $H_{t}=H^{e}\left(B_{t}\right)$ into $B_{t+1}=B\left(H_{t}, B_{t}\right)$ :

$$
B_{t+1}=B\left(H^{e}\left(B_{t}\right), B_{t}\right) \equiv\left(1-\gamma_{l}-\gamma_{h}\right)\left\{\left[w_{H}-(1+r) e\right]+(1+r) B_{t}\right\} .
$$

Note that the equation does not depend on $F_{t}$. The fixed point of the equation $B^{* *}$ is

$$
B^{* *}=\frac{1-\gamma_{l}-\gamma_{h}}{1-\left(1-\gamma_{l}-\gamma_{h}\right)(1+r)}\left[w_{H}-(1+r) e\right]
$$




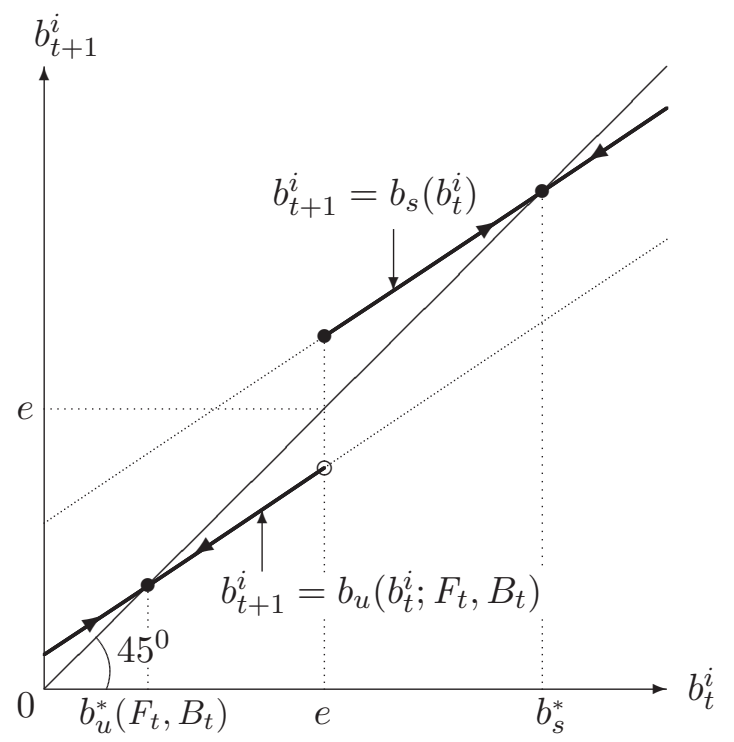

Figure 2: Unequal opportunity case when $b_{u}^{*}\left(F_{t}, B_{t}\right) \leq e$

which is equal to $\left(b_{s}\right)^{*}$ and globally stable. And the number of skilled workers at $B^{* *}, H^{* *} \equiv$ $H^{e}\left(B^{* *}\right)$, equals

$$
\begin{aligned}
H^{* *} & \equiv H^{e}\left(B^{* *}\right)=\left(1-\gamma_{l}\right)-\frac{\gamma_{l}(1+r) B^{* *}}{\left[w_{H}-(1+r) e\right]}, \\
& =1-\frac{\gamma_{l}}{1-\left(1-\gamma_{l}-\gamma_{h}\right)(1+r)} .
\end{aligned}
$$

\subsubsection{Dynamics of $F_{t}$}

Next, the dynamics of $F_{t}$, the proportion of people who can afford education, are examined for given $B_{t}$. Unlike aggregate transfers, the dynamic equation relating $F_{t}$ to $F_{t+1}$ depends on the distribution of transfers over the population, so it cannot be derived without complete information on the distribution. However, the direction of change of $F_{t}$ can be known only with current values of the two aggregate variables, $B_{t}$ and $F_{t}$.

Assume that $\left(1-\gamma_{l}-\gamma_{h}\right) w_{H} \geq e$, i.e. $B^{* *}=b_{s}^{*} \geq e$, is satisfied. Note that this assumption places a restriction not on the productivity of sector $\mathrm{H}$ but on the degree of altruism. Since $e=s_{e} w_{H}$, it can be rewritten as $1-\gamma_{l}-\gamma_{h} \geq s_{e}$, which implies that people are altruistic enough towards their children. From the assumption, $F_{t}$ is non-decreasing over time, because $b_{t+1}^{i} \geq e$ is satisfied whenever $b_{t}^{i} \geq e$ is true (see Figure 2).

First, consider the unequal opportunity case, in which transfers of unskilled workers change over time according to $b_{t+1}^{i}=b_{u}\left(b_{t}^{i} ; F_{t}, B_{t}\right)$. Whether $F_{t}$ remains constant or increases over time is determined by the relative size of $b_{u}^{*}\left(F_{t}, B_{t}\right)$ to $e$. When $b_{u}^{*}(:) \leq e$, none of offspring of unskilled workers receive transfers greater than $e\left(b_{t}^{i}<e\right.$ implies $\left.b_{t+1}^{i}<e\right)$, so $F_{t}$ is constant (see Figure 2). In contrast, when $b_{u}^{*}(:)>e$ is satisfied, $F_{t+1} \geq F_{t}$ holds, because, depending on the distribution of transfers, education may become affordable to children of a portion of unskilled workers (see Figure 


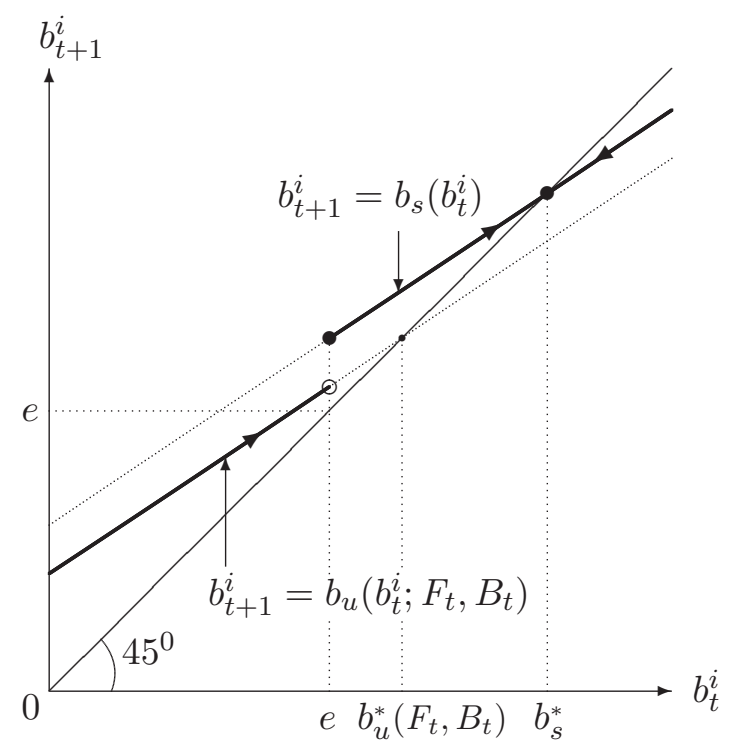

Figure 3: Unequal opportunity case when $b_{u}^{*}\left(F_{t}, B_{t}\right)>e$

3). And $F_{t}$ definitely increases in the longer term, when $b_{u}^{*}(:)>e$ continues to hold for sufficiently many periods. From $(21)$, the dividing line $b_{u}^{*}\left(F_{t}, B_{t}\right)=e$ is given by

$$
B_{t}=\frac{1-\left(1-\gamma_{l}-\gamma_{h}\right)(1+r)}{\left(1-\gamma_{l}-\gamma_{h}\right)(1+r)} \frac{1-\gamma_{l}}{\gamma_{l}} e\left(1-F_{t}\right)-\frac{\left[w_{H}-(1+r) e\right] F_{t}}{1+r}
$$

Alternatively, in the equal opportunity case, transfers of the both types of workers follow $b_{t+1}^{i}=$ $b_{s}\left(b_{t}^{i}\right)$, and $F_{t+1} \geq F_{t}$ is satisfied.

\subsubsection{Joint dynamics of $F_{t}$ and $B_{t}$}

Finally, the dynamics of $F_{t}$ and $B_{t}$ are analyzed together by introducing the phase diagram (Figure 4 ), in which the horizontal axis represents $F$ and the vertical axis represents $B .{ }^{18,19}$ Feasible combinations of $F$ and $B$ are equal to the area bound by $F=0, F=1$, and $B=e F$. The economy must satisfy $B \geq e F$, because $F$ is defined as the fraction of individuals who have received transfers $b^{i}$ greater than the cost of education $e$.

The diagram is divided into two regions, one corresponding to the unequal opportunity case and the other region for the equal opportunity case (dotted area), by $F=H^{e}(B)$, (22). The region below the locus is the unequal opportunity case, where all the individuals who can afford education take education and become skilled workers, i.e. $H=F$. The region above it is the equal opportunity case, in which the number of skilled workers is determined so that the return from

\footnotetext{
${ }^{18} \mathrm{~A}$ more formal analysis of the dynamics of the aggregate variables is available from the author upon request.

${ }^{19}$ Even when sector $\mathrm{L}$ is interpreted as traditional agriculture and thus land is included in the production function (see footnote 11), the qualitatively same phase diagram can be drawn and thus all the qualitative results in this section remain intact. In particular, when agricultural output is shared equally among unskilled workers (and thus the sector's valued added equals total unskilled labor income), the phase diagram is identical to the diagram of the original model. When the unskilled wage and the rental rate of land are determined competitively, intercepts and slopes of the lines in the diagram change slightly, but the shape of the diagram is not affected.
} 


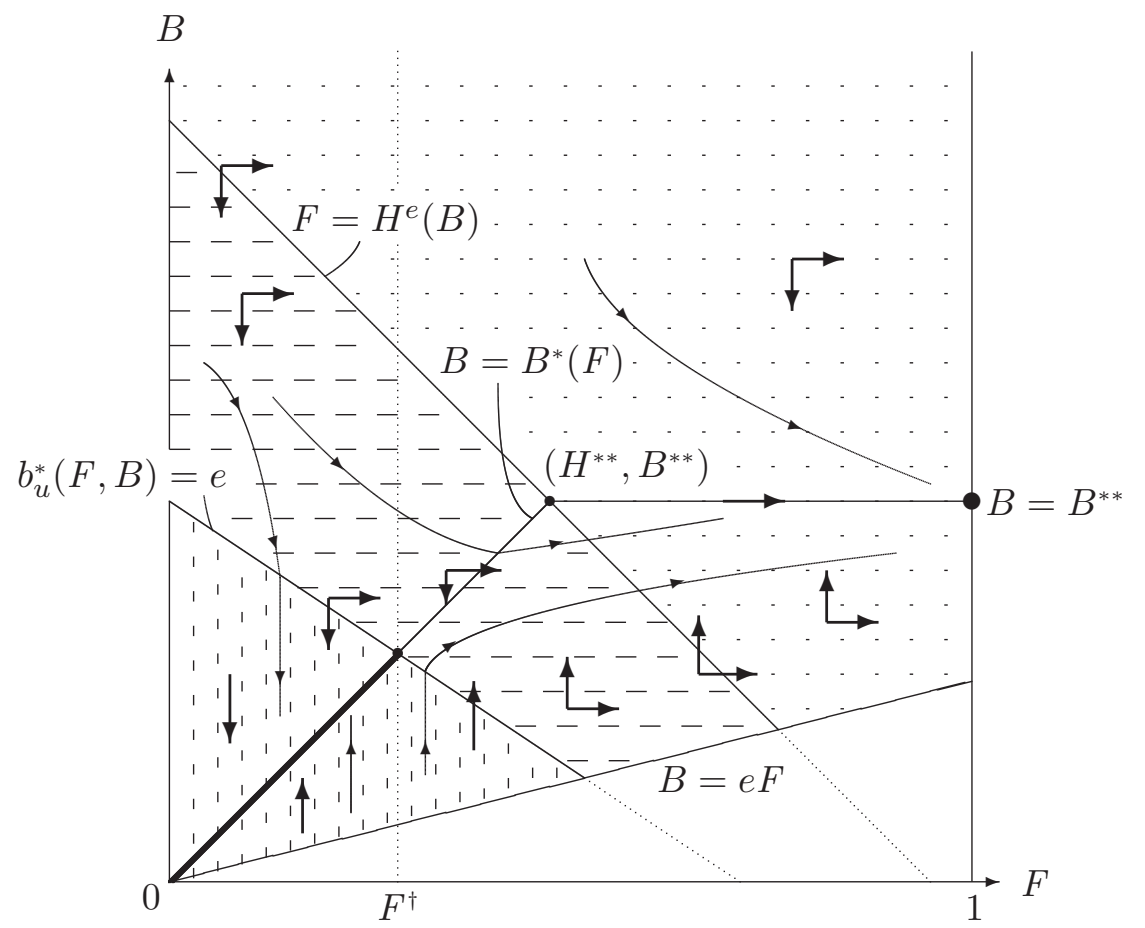

Figure 4: Phase diagram

education is equated with the return from assets, i.e. $H=H^{e}(B) \leq F$.

In the unequal opportunity case, the direction of motion of $B$ is determined by the position of current $\left(F_{t}, B_{t}\right)$ relative to $B=B^{*}(F),(24)$. When the current economy is located on the line, $B_{t}$ is constant; when located above (below), it decreases (increases) over time. The direction of change of $B$ in each region is expressed with vertical arrows. As for the direction of change of $F=H$, it is determined by the location of $\left(F_{t}, B_{t}\right)$ relative to $b_{u}^{*}(F, B)=e$. In the region below or on the line (the area with vertical dashed lines), $b_{u}^{*}(:) \leq e$ is satisfied, accordingly $F_{t+1}=F_{t}$ holds; in the region above the line (the area with horizontal dashed lines), $b_{u}^{*}(:)>e$, hence $F_{t+1} \geq F_{t}$ is satisfied (and $F_{t}$ increases in the longer term, if the economy stays in the region for sufficiently many periods). Alternatively, in the equal opportunity case, the direction of motion of $B$ is determined by the relative location to $B=B^{* *},(26)$, and $F_{t+1} \geq F_{t}$ always holds.

With this diagram, qualitative properties of transitional dynamics and the long-run outcome of the aggregate variables $(F, B)$ are transparent. Except when $B>B^{*}(F), b_{u}^{*}(F, B)>e$, and $F<H^{* *}$ are simultaneously satisfied, they are completely known only with the position of $\left(F_{t}, B_{t}\right)$ in the diagram. 


\section{Analyses}

\subsection{Initial distribution and long-run economic structure}

By using this diagram, the relationship between the initial distribution of wealth and the long-run structure of the economy along with its transition can be easily investigated.

First, consider an economy that attains equal opportunity from the beginning, whose initial position is in the dotted area of the diagram. Since returns from the two investment opportunities are equated, the both types of workers earn the same level of earnings (net of the cost of education), and education becomes affordable to children of poor unskilled workers over time ( $F$ increases). As long as the economy starts with $F_{0}>F^{\dagger}\left(F^{\dagger}\right.$ is defined as the value of $F$ at the intersection of $b_{u}^{*}(F, B)=e$ and $\left.B=B^{*}(F)\right)$, it converges to $(F, B)=\left(1, B^{* *}\right)$ for certain, where not only the net earnings but also net income and wealth are equalized and $b^{i}=b_{s}^{*}$ holds. That is, perfect equality is attained. The long-run outcome of the economy with $F_{0} \leq F^{\dagger}$, by contrast, depends on the exact initial distribution. If wealth is highly concentrated in the rich, $F$ would increase only slightly and the economy may regress to the unequal opportunity case (crosses the line $F=H^{e}\left(B_{t}\right)$ ). Otherwise, it would converge to $\left(1, B^{* *}\right)$.

Next, examine an economy that starts from the area with horizontal dashed lines. It does not satisfy equal opportunity initially, but children of unskilled workers gain access to education over time ( $F$ increases). Thus, the number of skilled workers increases and wage inequality between skilled and unskilled workers diminishes. Associated with this change, production and employment shares of sector $\mathrm{H}$ rise, while those of sector $\mathrm{L}$ fall. When $F_{0}>F^{\dagger}$, the economy attains equal opportunity at some point and perfect equality is realized in the long run. On the other hand, when $F_{0} \leq F^{\dagger}$, the long-run outcome depends on the exact initial distribution. If the distribution is concentrated in the few rich, the number of skilled workers increases only slightly over time, and it is possible that the economy crosses $b_{u}^{*}(:)=e$.

The remaining scenario is that an economy starts from the area with vertical dashed lines, where not only investment opportunities are unequal but also children of unskilled workers cannot access education, i.e. $b_{u}^{*}(:) \leq e$. Since the number of skilled workers is constant, the sectoral composition of production and employment remains unchanged. In particular, if $F_{0} \leq F^{\dagger}$, the economy converges to $\left(F_{0}, B^{*}\left(F_{0}\right)\right)$, and unequal opportunity and inequality persist in the long run. If the economy starts with $F_{0}>F^{\dagger}$, its long-run prospect is much brighter. While asset accumulation is low, poor people cannot afford education and hence the number of skilled workers remains constant. But, after a certain amount of asset accumulation, the economy transits to $b_{u}^{*}(:)>e$ and the sectoral shift starts. In the long run, it attains equal opportunity and perfect equality. 
The analysis has shown that there is a clear-cut relationship between the initial distribution of wealth and the attainment of the structural change and equal opportunity in the long run. That is, if the initial distribution is such that the fraction of individuals who have enough resources to take education is low, the economy remains stagnant. Thus, the initial size of 'middle class' matters for development through sectoral change. Note that equal distribution does not always lead to development: if initial aggregate wealth is very low, too equal wealth distribution implies $F_{0} \leq F^{\dagger}$ and results in stagnation. Further, if the economy starts below the critical level of asset accumulation, $B_{0}=F^{\dagger} e$, it remains stagnant irrespective of the initial distribution.

When productivity growth is introduced into the model, all the variables except $F$ grow over time even in the long run, but the qualitatively same phase diagram can be drawn, after the nonstationary variables are adjusted for the productivity growth of sector $\mathrm{H}$. Hence, all the qualitative results in this subsection remain unchanged. ${ }^{20}$ Without the productivity growth, the sectoral shift is necessarily associated with a rise of the relative price of good L, but now the relative price may decrease over time if the productivity growth of sector $\mathrm{L}$ is large enough.

\subsection{Comparisons among long-run equilibria}

There are two kinds of steady state equilibria, $\left(F_{s s}, B_{s s}\right)=\left(1, B^{* *}\right)$ and $\left(F, B^{*}(F)\right)$, where $F \leq F^{\dagger}$. In the former equilibrium, the number of skilled workers is $H^{* *}$, the skilled wage (net of the cost of education) is equal to the unskilled wage, and all individuals hold the same level of wealth, $\frac{1}{1-\gamma_{l}-\gamma_{h}}\left(b_{s}\right)^{*}{ }^{21}$ On the other hand, in the latter type of equilibria, the number of skilled workers is $F\left(\leq F^{\dagger}<H^{* *}\right)$, the (net) skilled wage is higher than the unskilled wage, and the wealth of skilled workers, $\frac{1}{1-\gamma_{l}-\gamma_{h}}\left(b_{s}\right)^{*}$, is greater than that of unskilled workers, $\frac{1}{1-\gamma_{l}-\gamma_{h}} b_{u}^{*}\left(F, B^{*}(F)\right)$. The relative price of good L, $P\left(H, B^{*}(H)\right)$, is increasing in $H$, so are $w_{L}\left(H, B^{*}(H)\right)$ and $b_{u}^{*}\left(H, B^{*}(H)\right)$.

These steady state equilibria can be ranked in terms of the wage and wealth of unskilled workers, which may be also interpreted as measures of inequality between skilled and unskilled workers, ${ }^{22}$ and of the total wealth of the economy. ${ }^{23}$ The best equilibrium is $\left(1, B^{* *}\right)$, then among equilibria $\left(F, B^{*}(F)\right), F \leq F^{\dagger}$, one with larger $F$ is better. The ranking, however, does not take into account

\footnotetext{
20 The detailed analysis is available from the author upon request. One thing to note is that both $H^{* *}$ and $F^{\dagger}$ increase with the growth rate of sector $\mathrm{H}$ productivity. That is, with the faster productivity growth, the number of skilled workers and thus the size of sector $\mathrm{H}$ become greater in the equal opportunity steady state, but it becomes more difficult for an economy with a small size of 'middle class' to initiate the sectoral shift. Thus, the productivity growth of the modern sector enhances the disparity of the long-run outcome among economies with different initial conditions.

${ }^{21}$ Wealth is defined as $w_{H}-(1+r) e+(1+r)\left(b_{s}\right)^{*}$.

${ }^{22}$ Remember that the wage and wealth of skilled workers are same in all the steady state equilibria. Interestingly, Deininger and Squire (1998) finds that initial land and income inequality affect negatively income growth of the poor, but not of the rich.

${ }^{23}$ Total wealth at equilibrium $\left(1, B^{* *}\right)$ equals $\frac{1}{1-\gamma_{l}-\gamma_{h}}\left(b_{s}\right)^{*}$, while at equilibria $\left(F, B^{*}(F)\right), F<F^{\dagger}$, it is equal to $\frac{1}{1-\gamma_{l}-\gamma_{h}}\left(b_{s}\right)^{*} \frac{F}{H^{* *}}$.
} 
the fact that the relative price of good L is different across the equilibria. For accurate welfare comparisons, the utility of each type of workers needs to be computed. Still, the ordering among the steady state equilibria remains unchanged, if the average utility, which can be interpreted as the expected utility of an individual before birth, is used for the comparison. ${ }^{24}$

\subsection{Mechanism behind the results}

The mechanism of the model yielding the above results can be explained intuitively by the following illustration (see Figure 4). Consider an economy in which skilled workers are scarce $\left(H_{0}=F_{0}<\right.$ $\left.H^{* *}\right)$ and its asset accumulation is modest $\left(B_{0}<B^{*}\left(H_{0}\right)\right)$ initially. How can this economy raise its income level? One route is through further asset accumulation. Many individuals leave more than they received from parents to children. The growth of wealth raises the demand for good $\mathrm{L}$, its price, and the unskilled wage. The increased unskilled wage then stimulates savings by unskilled workers, further promoting asset accumulation. This process continues until aggregate assets reach the steady state level. However, with the number of skilled workers constant, the income growth is moderate since the ultimate source of asset accumulation is labor income. Further, inequality between skilled and unskilled workers remains large because the investment opportunities are constrained by family income.

Thus, in order to attain large income growth, an increase in the number of skilled workers and the sectoral shift of production and employment from sector $\mathrm{L}$ to sector $\mathrm{H}$ is crucial. The sectoral shift starts iff a fraction of children of unskilled workers receive enough resources to take education, which is possible when the unskilled wage $w_{L, t}=P_{t} A_{L}$ and thus the relative price of good L are above critical levels. The relative price depends positively on the number of skilled workers and aggregate assets: the demand for good L increases with the both variables, while its supply decreases with the number of skilled workers. Hence the two variables must be above certain

${ }^{24}$ At equilibrium $\left(1, B^{* *}\right)$, the both types of workers have the same utility level:

$$
U\left(1, B^{* *}\right)=\frac{\gamma_{l}^{\gamma_{l}} \gamma_{h}^{\gamma_{h}}\left(1-\gamma_{l}-\gamma_{h}\right)^{1-\gamma_{l}-\gamma_{h}}}{1-\left(1-\gamma_{l}-\gamma_{h}\right)(1+r)}\left(A_{L}\right)^{\gamma_{l}}\left[w_{H}-(1+r) e\right]^{1-\gamma_{l}}
$$

At equilibria $\left(F, B^{*}(F)\right), F \leq F^{\dagger}$, the utility of skilled workers is given by

$$
U_{s}\left(F, B^{*}(F)\right)=U\left(1, B^{* *}\right) \cdot\left(\frac{1-H^{* *}}{H^{* *}} \frac{F}{1-F}\right)^{-\gamma_{l}}
$$

$U_{s}\left(F, B^{*}(F)\right)>U\left(1, B^{* *}\right)$ is satisfied since $F<H^{* *}$. Intuitively, their utility level is higher than at equilibrium $\left(1, B^{* *}\right)$ because good $\mathrm{L}$ is cheaper. In contrast, unskilled workers have lower utilities than at $\left(1, B^{* *}\right)$ :

$$
U_{u}\left(F, B^{*}(F)\right)=U\left(1, B^{* *}\right) \cdot\left(\frac{1-H^{* *}}{H^{* *}} \frac{F}{1-F}\right)^{1-\gamma_{l}} .
$$

Note that $U_{s}\left(F, B^{*}(F)\right)$ is decreasing and $U_{u}\left(F, B^{*}(F)\right)$ is increasing in $F$, so inequality in welfare decreases with $F$. Finally, the average utility is given by

$$
E\left[U\left(H, B^{*}(H)\right)\right]=U\left(1, B^{* *}\right) \cdot\left(\frac{H}{H^{* *}}\right)^{1-\gamma_{l}}\left(\frac{1-H}{1-H^{* *}}\right)^{\gamma_{l}},
$$

which is increasing in $H$ and attains the highest value at $H=H^{* *}$, since $H \leq H^{* *}<1-\gamma_{l}$. 
levels for the 'take-off', i.e. $b_{u}^{*}(F, B)>e$.

When the economy begins with an asset distribution satisfying $F_{0}>F^{\dagger}$, the relative price of good L and the unskilled wage are not very low. If the combination of $F_{0}$ and $B_{0}$ satisfies $b_{u}^{*}\left(F_{0}, B_{0}\right)>e$, a wealthier portion of unskilled workers can send their children to school and the sectoral shift starts immediately. Otherwise, children of unskilled workers cannot access education initially. However, after continued asset accumulation, the relative price reaches the critical level at some point and the economy 'take offs'. Once the sectoral shift starts, it continues autonomously. An increase in the number of skilled workers and the resulting asset accumulation raise the demand for good L, reduces its supply, and contributes to further rises in the relative price and the unskilled wage. Accordingly, children of less affluent unskilled workers gain access to education and the number of skilled workers grows further. This virtuous cycle continues, as long as the skilled wage (net of the cost of education) is higher than the unskilled wage and thus financially eligible individuals always take education and become skilled workers. The wage differential decreases over time, however, and the virtuous cycle ends when the net wages are equated. ${ }^{25}$ After equal opportunity is attained, the unskilled wage stays constant, but the size of 'middle class' and aggregate transfers continue to increase until they reach the steady state levels, $\left(F_{s s}, B_{s s}\right)=\left(1, B^{* *}\right)$.

In contrast, when the economy starts with a wealth distribution satisfying $F_{0} \leq F^{\dagger}$, the initial number of skilled workers is small and the unskilled wage is low. Children of unskilled workers are not financially eligible for education and cannot become skilled workers. Still, the relative wage increases over time through asset accumulation, but it never reaches the critical level for the sectoral shift. With the number of skilled workers constant, inequality between skilled and unskilled workers does not disappear, and the economy ends up with equilibria with lower output and unequal distribution, $\left(F_{s s}, B_{s s}\right)=\left(F, B^{*}(F)\right), F \leq F^{\dagger}$.

When initial asset accumulation is relatively large for the number of skilled workers $\left(B_{0}>\right.$ $\left.B^{*}\left(H_{0}\right)\right)$, the relative price of good $\mathrm{L}$ and the unskilled wage are higher and thus the sectoral shift starts more easily. However, unless $F_{0}>F^{\dagger}$, the convergence to the best steady state is not assured. The reason is that the ultimate source of asset accumulation is labor income. Since initial asset accumulation exceeds the level that labor income can support in the long run, there is a tendency for wealth to decrease over time. If initial wealth is concentrated in the few rich and the number of skilled workers increases only moderately, wealth does decrease over time and the economy ends up in an unequal steady state.

\footnotetext{
${ }^{25}$ Psacharopoulos $(1989,1994)$ find that returns to education are higher in low-income nations especially at primary and secondary education levels.
} 


\section{$5 \quad$ Introducing the sectoral shift of consumption}

The analysis so far has employed the Cobb-Douglas utility function, and hence has abstracted from the sectoral shift of consumption from the traditional sector (sector L) to the modern sector (sector $\mathrm{H})$. It is a stylized fact that consumers spend more of their incomes on skill-intensive goods and transfers as their income levels go up (see, for example, Syrquin, 1988, for the evidence). In this section, the utility function is modified so that this feature can be observed in the model. After the modification, the productivity of sector $L$ as well as initial wealth distribution become determinants of the long-run structure of the economy. In particular, it is shown that if the productivity of sector $\mathrm{L}$ is sufficiently low, it ends up in a steady state with low output and high inequality regardless of the initial distribution and the productivity of the modern sector.

\section{$5.1 \quad$ Model}

The modified utility function takes the following form:

$$
U_{t}^{i}=\left(c_{L, t}^{i}-\widetilde{c_{L}}\right)^{\gamma_{l}}\left(c_{H, t}^{i}\right)^{\gamma_{h}}\left(b_{t+1}^{i}\right)^{1-\gamma_{l}-\gamma_{h}} .
$$

The constant $\widetilde{c_{L}}$ may be interpreted as the minimum consumption level of good $\mathrm{L}$ needed for subsistence, when good L is interpreted as basic agricultural goods. A consumer maximizes the new utility subject to the budget constraint,

$$
P_{t} c_{L, t}^{i}+c_{H, t}^{i}+b_{t+1}^{i}=w_{t}^{i}+(1+r) a_{t}^{i}
$$

where $w_{t}^{i}$ is earnings and $a_{t}^{i}$ is the investment in assets made in the previous period (childhood).

By solving the maximization problem, the following consumption and transfer rules are obtained:

$$
\begin{aligned}
P_{t} c_{L, t}^{i} & =\gamma_{l}\left[w_{t}^{i}+(1+r) a_{t}^{i}\right]+\left(1-\gamma_{l}\right) P_{t} \widetilde{c_{L}}, \\
c_{H, t}^{i} & =\gamma_{h}\left[w_{t}^{i}+(1+r) a_{t}^{i}-P_{t} \widetilde{c_{L}}\right], \\
\text { and } b_{t+1}^{i} & =\left(1-\gamma_{l}-\gamma_{h}\right)\left[w_{t}^{i}+(1+r) a_{t}^{i}-P_{t} \widetilde{c_{L}}\right] .
\end{aligned}
$$

The consumer first spends the wealth $w_{t}^{i}+(1+r) a_{t}^{i}$ to purchase the minimum level of good L, $\widetilde{c_{L}}$, then allocates the rest of the wealth to the goods and transfer in fixed proportions. As income grows, the share of the wealth spent on good L falls and the shares spent on good $\mathrm{H}$ and the transfer rise, unless $P_{t}$ grows faster than the wealth. The price elasticity of good $\mathrm{L}$ is less than one, while those of good $\mathrm{H}$ and the transfer are more than one.

Sectoral productivities are assumed to be time-invariant except in Section 5.5. Since the market 
structure is the same as before, the wages of skilled and unskilled workers are given by the same equations, $w_{H}=\alpha\left(A_{H}\right)^{\frac{1}{\alpha}}\left(\frac{1-\alpha}{r}\right)^{\frac{1}{\alpha}-1}$ and $w_{L, t}=P_{t} A_{L}$.

The market clearing condition of good $\mathrm{L}$ is different from the one in the previous model because of the term associated with $\widetilde{c_{L}}$ :

$$
P_{t} A_{L} L_{t}=\gamma_{l}\left[w_{L, t} L_{t}+w_{H} H_{t}+(1+r) \sum_{i} a_{t}^{i}\right]+\left(1-\gamma_{l}\right) P_{t} \widetilde{c_{L}}
$$

Remember that $L_{t}$ is the number of unskilled workers, $H_{t}$ is the number of skilled workers, and $\sum_{i} a_{t}^{i}$ is aggregate assets. Substituting $w_{L, t}=P_{t} A_{L}, L_{t}=1-H_{t}$, and $\sum_{i} a_{t}^{i}=B_{t}-e H_{t}$ into the above equation, and solving it for $P_{t}$, the relative price of good L is given by

$$
P_{t}=P\left(H_{t}, B_{t}\right) \equiv \frac{\gamma_{l}}{1-\gamma_{l}} \frac{\left[w_{H}-(1+r) e\right] H_{t}+(1+r) B_{t}}{A_{L}\left(1-H_{t}\right)-\widetilde{c_{L}}}
$$

It is assumed that the productivity of sector $\mathrm{L}$ is high enough $\left(A_{L}>\widetilde{c_{L}}\right)$ that the economy can support at least the minimum level of consumption $\widetilde{c_{L}}$, if the whole population is in sector L. With the presence of $\widetilde{c_{L}}$, higher productivity $A_{L}$ lowers $P_{t}$ more than proportionately, because people spend smaller portions of their incomes on good L.

Derivations of dynamic equations of individual and aggregate transfers are explained in Appendix. Here, major properties of the equations and of variables needed to analyze the joint dynamics of $F_{t}$ and $B_{t}$ are summarized. In the unequal opportunity case, i.e. $w_{H}-(1+r) e>w_{L}\left(F_{t}, B_{t}\right)$, the dynamic equation of a skilled worker, $b_{t+1}^{i}=b_{s}\left(b_{t}^{i} ; F_{t}, B_{t}\right)$, and its fixed point, $b_{s}^{*}\left(F_{t}, B_{t}\right)$, now depend negatively on $F_{t}$ and aggregate transfers $B_{t}$ through $P_{t}$. Increases in $F_{t}$ and $B_{t}$ raise the price of good L, forcing her to increase spending on the minimum level of consumption, $\widetilde{c_{L}}$, and reduce a transfer. By contrast, the dynamic equation of an unskilled worker and its fixed point, $b_{u}^{*}\left(F_{t}, B_{t}\right)$, depend positively on $F_{t}$ and $B_{t}$ through $P_{t}$, because the effect of $P_{t}$ on her wage exceeds the effect on the expenditure on $\widetilde{c_{L}}$. In the equal opportunity case, i.e. $w_{H}-(1+r) e \leq w_{L}\left(F_{t}, B_{t}\right)$, the dynamic equation and its fixed point, $b^{*}$, are independent of $F_{t}$ and $B_{t}$, and the dividing line between the two cases, $F_{t}=H^{e}\left(B_{t}\right)$, decreases with $B_{t}$, as in the previous model. The dynamic equation of $B_{t}$ in the unequal opportunity case is same as before and its fixed point, $B^{*}\left(F_{t}\right)$, increases with $F_{t}$. In the equal opportunity case, the fixed point of the dynamics, $B^{* *}$, equals $b^{*}$ and the number of skilled workers at $B^{* *}$ is denoted $H^{* *}$. As seen below, unlike the model with $\widetilde{c_{L}}=0$, $A_{L}$ affects these variables (except $\left.B^{*}\left(F_{t}\right)\right)$ and thus the dynamics of $F_{t}$ and $B_{t}$. 


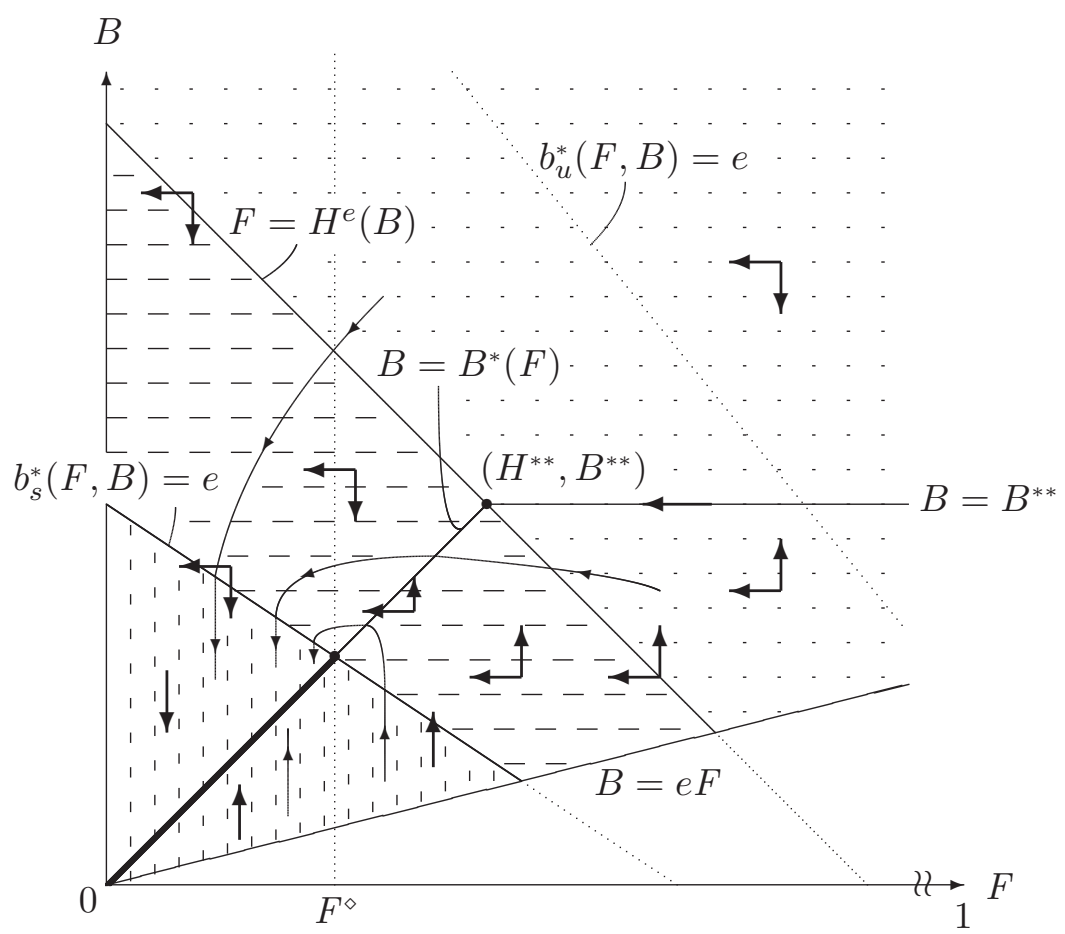

Figure 5: Economy with the sectoral shift of consumption: low productivity in sector L

\subsection{Joint dynamics of $F_{t}$ and $B_{t}$}

As before, the joint dynamics of $F_{t}$ and $B_{t}$, and relationship between initial wealth distribution and the long-run performance of an economy are investigated using a phase diagram. ${ }^{26}$

High productivity in sector L: When the productivity of sector $\mathrm{L}$ is high enough that $A_{L}[(1-$ $\left.\left.\gamma_{l}-\gamma_{h}\right) w_{H}-e\right]>\left(1-\gamma_{l}-\gamma_{h}\right)\left[w_{H}-(1+r) e\right] \widetilde{c_{L}}$, or $A_{L}\left(1-\gamma_{l}-\gamma_{h}-s_{e}\right)>\left(1-\gamma_{l}-\gamma_{h}\right)\left[1-(1+r) s_{e}\right] \widetilde{c_{L}}$, is satisfied, the phase diagram looks like the one in Section 3 (Figure 4). ${ }^{27}$ The qualitative nature of the dynamics remains unchanged in this case. That is, when the economy starts with a relatively equal wealth distribution and sufficient aggregate wealth, it converges to the equal opportunity steady state, i.e. $(F, B)=\left(1, B^{* *}\right)$; when the economy begins with an unequal wealth distribution or too small aggregate wealth, it converges to an unequal opportunity steady state, i.e. one of $(F, B)=\left(F, B^{*}(F)\right), F \leq F^{\dagger}$.

Low productivity in sector L: By contrast, when $A_{L}\left(1-\gamma_{l}-\gamma_{h}-s_{e}\right)<\left(1-\gamma_{l}-\gamma_{h}\right)\left[1-(1+r) s_{e}\right] \widetilde{c_{L}}$ is satisfied, that is, when the productivity of sector L is low, the phase diagram looks like Figure 5.

\footnotetext{
${ }^{26}$ Unlike the model without the sectoral shift of consumption, when land is included in the production function of sector $\mathrm{L}$ (see footnotes 11 and 19), the loci in the diagram except $B=B^{* *}$ and $B=e F$ become nonlinear. However, the phase diagram and thus the dynamics are qualitatively same as the original model. As seen just below, when the productivity of sector L is high, the dynamics are as analyzed in the previous section, while, when the productivity is low, the dynamics are as depicted in Figure 5 below. Effects of land on results are similar to sector L productivity.

${ }^{27}$ There are two minor differences from the model with $\widetilde{c_{L}}=0$. First, $F=H^{e}(B)$ shifts inwards by factor $\left(1-\frac{\widetilde{c_{L}}}{A_{L}}\right)$. Second, the slope of $b_{u}^{*}(F, B)=e$ becomes steeper by the presence of $\left(1-\frac{\widetilde{c_{L}}}{A_{L}}\right)$. See Appendix.
} 
Unlike the previous case, $b_{u}^{*}(F, B)=e$ is located above $F=H^{e}(B)$, hence $b_{u}^{*}(H, B)<e$ is satisfied for all the feasible combinations of $(H, B),{ }^{28}$ while $b_{s}^{*}(F, B)=e$ is located below $F=H^{e}(B) .{ }^{29}$ Consequently, descendants of unskilled workers never accumulate enough assets to become skilled workers. Since $b_{s}^{*}(F, B)$ is decreasing in $F$ and $B$, in the region above $b_{s}^{*}(F, B)=e, b_{s}^{*}(:)<e$ and thus $F_{t+1} \leq F_{t}$ are satisfied, while in the region below or on the line, $b_{s}^{*}(:) \geq e$ and $F_{t+1}=F_{t}$ hold. In the diagram, $F^{\diamond}$ is the value of $F$ at the intersection of $b_{s}^{*}(F, B)=e$ and $B=B^{*}(F)$.

Based on the diagram, relationship between initial wealth distribution and the long-run outcome of an economy is examined. The most notable difference from the results of the previous case and of the model with $\widetilde{c_{L}}=0$ is that equal opportunity and perfect equality are not sustained in the long run. In the equal opportunity case (dotted area), $b^{*}<e$ holds and thus the proportion of individuals financially qualified for education decreases over time. Consequently, the economy transits to the unequal opportunity case at some point. In the unequal opportunity case, as long as the economy is located above $b_{s}^{*}(F, B)=e$, the number of skilled workers decreases over time. Thus, the long-run equilibria of the economy are $(F, B)=\left(F, B^{*}(F)\right), F \leq F^{\diamond}$, where the (net) skilled wage is higher than the unskilled wage and unequal opportunity persists. Among the steady state equilibria, one with greater $F$ achieves lower inequality and higher total income.

\subsection{Analyses}

With the introduction of the sectoral shift of consumption, the long-run outcome of the economy becomes dependent on the productivity of sector L. Why doesn't the economy succeed in the sectoral shift when the productivity of the traditional sector is low? The requirement for the structural change is sizable wealth accumulation by a portion of unskilled workers so that they can send their children to school. How does the lower productivity affect their transfers? Remember that they have to consume at least $\widetilde{c_{L}}$ units of good L irrespective of its price, so the price elasticity of demand for the good is less than one. Accordingly, when the productivity of sector L decreases, the relative price of good L rises more than proportionately, thus the unskilled wage too goes up, other things being equal. The higher wage allows unskilled workers to spend more on transfers, while the price increase forces them to raise the expenditure on good L. It turns out that the former effect dominates and transfers increase: ${ }^{30}$ with smaller $F$ and $B$, a portion of children of unskilled workers can achieve the upward mobility, i.e. $b_{u}^{*}(F, B)=e$ is located closer to the origin in the

\footnotetext{
${ }^{28}$ The condition on the productivity is equivalent to $b^{*}<e$. Thus, in the equal opportunity case, $b_{u}^{*}(H, B)=$ $b_{u}^{*}\left(H^{e}(B), B\right)=b^{*}<e$ is satisfied. Then, $b_{u}^{*}(H, B)<e$ is satisfied for the unequal opportunity case as well, since $b_{u}^{*}(H, B)=b_{u}^{*}(F, B)<b_{u}^{*}\left(H^{e}(B), B\right)$.

${ }^{29}$ This is equivalent to $B^{* *}=b^{*}<e$. So $B=e F$ intersects with $B=B^{* *}$ at $F<1$ in this case.

${ }^{30}$ Note that their utilities do not necessarily increase, because the higher price reduces the consumption of good L. Only the very poor (those with little assets) are better off for certain.
} 
phase diagram. However, there is the other effect associated with the lower productivity and the resultant higher unskilled wage: because of the fall of return to education for given $F$ and $B$, the economy can sustain a smaller number of skilled workers under equal opportunity, i.e. $F=H^{e}(B)$ too is located closer to the origin. If the productivity of sector L is low enough, as in Figure 5, the second effect dominates the first one, i.e. $b_{u}^{*}(F, B)=e$ is located above $F=H^{e}(B)$, thus the sectoral shift never starts.

Further, when the economy starts with relatively large 'middle class', i.e. $F_{0}>F^{\diamond}$, it cannot maintain the initial size of skilled labor, because the relative price of good L is too high for all of skilled workers to leave transfers sufficient for education to their children. The number of skilled workers must decline until the relative price falls enough that they can leave the adequate transfers. In particular, the case where the economy starts with $F_{0}>F^{\diamond}$ and $b_{s}^{*}\left(F_{0}, B_{0}\right)>e$ (the area with vertical dashed lines) is worth mentioning. As long as $b_{s}^{*}(F, B) \geq e$ is satisfied, wealth accumulation (with constant $H=F$ ) raises the relative price of good $\mathrm{L}$ and the unskilled wage and lowers inequality between skilled and unskilled workers over time. However, once the economy enters the region $b_{s}^{*}(F, B)<e, H=F$ begins to decline, reversing the improving trend in the unskilled wage and the inequality. The rising price of good L chokes off the moderate development process eventually. ${ }^{31}$

The result shows that, when the sectoral shift of consumption is introduced, a moderate level of productivity in sector L becomes a prerequisite for the sectoral shift, and without it, the economy is destined to converge to a steady state with low output and high inequality. By contrast, without the sectoral shift of consumption, the structural change happens even when the productivity is low, as long as initial wealth distribution is 'right'. In this case, individuals always spend a fixed portion of their incomes on each of the goods and transfers, hence the productivity level does not affect the unskilled wage and transfer levels.

\subsection{Policy Implications}

Several policy implications can be drawn from the results. When the productivity of the traditional sector is low, policies intended to correct the distribution of wealth, including land redistribution and increased income transfers to the poor, alone do not lead to the structural change and the large improvement of income levels of the poor. For these policies to have greater impacts, policies enhancing the sector's productivity, such as the improvement of agricultural infrastructure and the better provision of governmental services to the urban informal sector, must be implemented

\footnotetext{
${ }^{31}$ Relatedly, the possibility that a rising food price produced in the traditional sector could stifle development process is shown in the Lewis (1954) model of a dual economy. The mechanism is that a wage increase caused by a rising food price reduces profits of the modern sector, lowers savings by capitalists and thus capital accumulation.
} 
simultaneously. ${ }^{32}$ Aid from foreign countries and international institutions would be much more effective, if it is allocated, for example, not only to school building projects in rural areas that help reducing the private cost of education, but also to the diffusion of knowledge on better farm practices. $^{33}$

Policies contributing to the higher productivity of the traditional sector, however, must be executed with great care. Without the sectoral shift of consumption, the higher productivity lowers the relative price of the traditional good, while it does not affect the wages and all the dynamic equations, hence welfare effects of the policies on all workers of present and future generations are definitely positive. With $\widetilde{c_{L}}>0$, in the unequal opportunity case, such policies lower the unskilled wage as well as the price, hence they have negative effects on the wage inequality and transfers by unskilled workers. Skilled workers benefit from the lower price, while descendants of unskilled workers suffer from lower wealth and their upward mobility may be halted. ${ }^{34}$ Hence, when sector L productivity is low (so that the phase diagram looks like Figure 5), for the structural change to be realized, the both types of policies must be carried out, unless $F_{t}$ is high enough. In the equal opportunity case, the higher productivity increases the welfare of all individuals, because it lowers the relative price and raises the number of skilled workers and asset accumulation. Thus, the productivity-enhancing policies are desirable even when the productivity is high (Figure 4). However, in this case, policies mitigating wealth inequality (or lowering the private cost of education) should be given a higher priority at an early stage of development. ${ }^{35}$

By contrast, policies raising the modern sector (sector $\mathrm{H}$ ) productivity increase steady state aggregate assets (without affecting the number of skilled workers in the equal opportunity steady state). However, they may hinder the upward mobility of descendants of unskilled workers in the high productivity case (lowers $F^{\dagger}$ ), because they increase the skilled wage and the cost of education at a higher rate than the unskilled wage. In the low productivity case, the inequality worsens without affecting the maximum number of skilled workers sustainable in the long run, $F^{\diamond}$.

\footnotetext{
${ }^{32} \mathrm{By}$ contrast, as mentioned in the introductory section, in the model of Galor and Zeira (1993), the inequalitycorrecting policies are sufficient for the attainment of equal opportunity.

${ }^{33}$ Unlike the redistributive policies, policies lowering the private cost of education, $e$, not only increase $F_{t}$ but also make the critical condition for the sectoral shift, $A_{L}\left[\left(1-\gamma_{l}-\gamma_{h}\right) w_{H}-e\right]>\left(1-\gamma_{l}-\gamma_{h}\right)\left[w_{H}-(1+r) e\right] \widetilde{c_{L}}$, more likely to be satisfied. However, because $A_{L}$ and $e$ enter multiplicatively in the condition, the effectiveness of the policies would be much greater if policies raising $A_{L}$ are executed at the same time.

${ }^{34}$ Note that aggregate wealth accumulation is not affected by the productivity (see equation 47 of Appendix). As for present unskilled workers, welfare effects of the policies are ambiguous, because the unskilled wage is lower but the traditional good is cheaper. A richer portion of unskilled workers is more likely to benefit.

${ }^{35}$ What should be avoided is that, as a result of the productivity-enhancing policies, an economy whose initial distribution has been conductive to the long-run attainment of equal opportunity ends up in an unequal opportunity steady state. In such economy, these policies should be conducted after the other policies ensure the convergence to the best steady state. By contrast, in the model of Galor and Zeira (1993), the higher productivity does not have any welfare effects in the equal opportunity case (just lowers the number of skilled workers), while, in the unequal opportunity case, it raises the unskilled wage and could improve the long-run outcome drastically and thus the productivity-improving policies are always beneficial.
} 
Hence, unless $F_{0}$ is sufficiently high, such policies should not be conducted on a large scale at a earlier stage of development. ${ }^{36}$

Finally, based on the policy implications, China's economic and education policies from the late 1970s are evaluated. When the Chinese government initiated economic reforms, China was a poor economy that was largely dependent on unproductive agriculture in rural areas. One of the first reforms tackled the sector's low productivity: the basic unit of production was transformed from a commune to a family farm and agricultural markets were partially liberalized. The purpose was to stimulate suppliers' incentives to raise productivity. Largely as a result of the reform, the growth of agricultural output accelerated in the early 1980s. As for the manufacturing sector, the emphasis was placed on the growth of industries intensive in unskilled labor: non-state but non-private Township-Village Enterprises (TVEs) in rural areas were permitted to enter industries not related to agriculture and led the sector's growth until the early 1990s, while foreign direct investment (FDI) was very limited during the period (Qian, 2003). ${ }^{37}$

The government started reforms in the education sector too. Educational expenditure was increased significantly: during the years 1950-78, 6.50\% of total government expenditure was allocated to education on average, which amounted to $2.20 \%$ of national income, while, for the years 1979-92, the proportion increased to $11.01 \%$, which was $2.88 \%$ of national income (Tsang, 2000). In 1985, it announced a major educational reform, including the achievement of nine-year compulsory education by $2000 . .^{38}$

These policies are consistent with the model's implications that, while the productivity of the traditional sector is low, policies enhancing the sector's productivity and policies enabling greater access to education should be implemented simultaneously, and productivity-enhancing policies to the modern sector should be limited in size. China's continuing phenomenal growth may be partly due to right choices of the policies at an early stage of transition to a market economy.

\subsection{Productivity growth}

The introduction of productivity growth does not largely change the main results of this section, but unlike the economy without the sectoral shift of consumption, the phase diagram is not qualitatively same as the constant productivity case. The reason is that, even after adjusted for the productivity growth of sector $\mathrm{H}, F=H^{e}\left(B ; A_{L, t}\right), b_{s}^{*}\left(F, B ; A_{L, t}\right)=e$, and $b_{u}^{*}\left(F, B ; A_{L, t}\right)=e$, shift upward with

\footnotetext{
${ }^{36}$ A similar implication is obtained in the Galor and Zeira (1993) model, when the cost of education is assumed to be proportional to the skilled wage.

${ }^{37}$ The reform of state firms, which dominated heavy industries, was initiated as early as 1978 , but it was not successful. The higher growth of industries intensive in unskilled labor may be partly due to the failure of the reform and not intended by the government.

${ }^{38}$ Although education itself was publicly provided, the indirect cost such as a commuting cost and the opportunity cost should have been important, considering, for example, urban-rural disparity in educational attainment.
} 
the growth of $A_{L, t}$. This complication brings some new phenomena to the dynamics. ${ }^{39}$

First, consider the case where the initial productivity of sector $\mathrm{L}$ is high so that the phase diagram in the initial period looks like the one in Section 3 (Figure 4 ). When $F_{0}$ is sufficiently large or small, the dynamics of $F_{t}$ and $B_{t}$ are qualitatively same as the constant productivity case. A new possibility arises when $F_{0}$ is of an intermediate size. In this situation, an economy initially experiencing sectoral shift may end up in an unequal opportunity steady state. This can happen if wealth is relatively concentrated in the rich, consequently an increase in the number of skilled workers cannot keep up with an outward shift of $b_{u}^{*}\left(F, B ; A_{L, t}\right)=e$ resulting from the productivity growth of sector L. Unskilled workers can increase transfers rapidly enough to keep up with a rising cost of education, if their income growth or a fall of the price of good L are fast enough. Given other things equal, the productivity growth makes the good cheaper but lowers the unskilled wage. ${ }^{40}$ The net effect on their asset accumulation is negative, that is, the growth of their transfers lag that of the cost of education. Hence, the sectoral shift is halted if the number of skilled workers and aggregate assets do not increase rapidly enough to support the unskilled wage.

When the initial productivity of sector L is low, the phase diagram in the initial period looks like the one presented earlier in this section (Figure 5). Clearly, due to the productivity growth, the economy shifts to the high productivity case (Figure 4) at some point. However, it is very unlikely that the economy starting from this situation succeeds in the sectoral shift and reaches the equal opportunity steady state in the long run. If the economy enters the high productivity case with small $F$, the structural change never starts. Entering the high productivity case with large $F$, on the other hand, requires sizable initial 'middle class' and rapid productivity growth in sector L, which is unlikely to be met in poor countries. ${ }^{41}$

\section{Conclusion}

There are two phenomena widely observed when an economy departs from an underdeveloped state and starts rapid economic growth: shifts of production, employment, and consumption from the traditional sector to the modern sector, and a large increase in educational levels of its population. The question is why some economies have succeeded in such 'structural change', but others do not. In order to examine the question, in particular, regarding contemporary developing economies, this paper has constructed an OLG model that explicitly takes into account the sectoral change and human capital accumulation as sources of development.

\footnotetext{
${ }^{39}$ The detailed analysis is available from the author upon request.

${ }^{40}$ The effects decrease with the productivity level and thus the model looks like the case of $\widetilde{c_{L}}=0$ in the long run.

${ }^{41}$ Effects of the productivity growth of sector $\mathrm{H}$ are qualitatively same as the case of $\widetilde{c_{L}}=0$ (footnote 20 ) with one additional result: when the initial productivity of sector $\mathrm{L}$ is low, the higher productivity growth is associated with lower $F^{\diamond}$.
} 
It has been shown that, for a successful structural change, an economy must start with an initial wealth distribution that enables a sufficient proportion of individuals to receive education. Once the economy initiates the 'take-off', the sectoral shift and human capital growth continue until it reaches the steady state where equal opportunity is attained. However, when the productivity of the traditional sector is low, the economy does not succeed in the sectoral shift irrespective of the initial distribution and modern sector productivity. Thus sufficient productivity in the traditional sector is a prerequisite for successful development.

The main points of the paper, (i) the importance of initial wealth distribution, especially the size of 'middle class', in economic development, and (ii) sufficient productivity in the traditional sector as a precondition for a successful sectoral shift, are largely supported by empirical studies. Supportive evidences on the second point are more indirect, and it may be worthwhile to test this point in a more formal manner. One simple test would be a regression of an economy's output growth on initial productivity in the traditional sector and other controls including an initial size of 'middle class'. The paper also shows that the priority of policies enhancing the productivity of the traditional sector over those correcting wealth inequality (or lowering the private cost of education) depends on the productivity level and the stage of development, which could be tested empirically.

\section{References}

[1] Aghion, Philippe and Patrick Bolton (1997) A trickle-down theory of growth and development with debt overhang. Review of Economic Studies 64(2), 151-172.

[2] Bairoch, Paul (1975) The Economic Development of the Third World since 1900. Berkeley and Los Angeles: University of California Press.

[3] Banerjee, Abhijit V. and Andrew F. Newman (1993) Occupational choice and the process of development. Journal of Political Economy 101(2), 274-298.

[4] Benabou, Roland (1996a) Heterogeneity, stratification, and growth: macroeconomic implications of community structure and school finance. American Economic Review 86(3), 584-609.

[5] Benabou, Roland (1996b) Inequality and growth. In Bernanke, Ben and Julio Rotemberg (eds.), NBER Macroeconomic Annual 1996, pp. 11-92. Cambridge, MA: MIT Press.

[6] Benhabib, Jess and Aldo Rustichini (1996) Social conflict and growth. Journal of Economic Growth 1(1), 129-146.

[7] Deininger, Klaus and Pedro Olinto (2000) Asset Distribution, Inequality, and Growth. Mimeo, World Bank. 
[8] Deininger, Klaus and Lyn Squire (1998) New ways of looking at old issues: inequality and growth. Journal of Development Economics 57(2), 259-287.

[9] Easterly, William (2001) The middle class consensus and economic development. Journal of Economic Growth 6(4), 317-35.

[10] Echevarria, Cristina (1997) Changes in sectoral composition associated with economic growth. International Economic Review 38(2), 431-52.

[11] Hansen, Gary D. and Edward C. Prescott (2002) Malthus to Solow. American Economic Review 92(4), 1205-1217.

[12] Hayami, Yujiro and Vernon Ruttan (1985) Agricultural Development: An International Perspective. Baltimore, MD: Johns Hopkins University Press.

[13] Galor, Oded, and Omer Moav (2004) From physical to human capital accumulation: inequality in the process of development. Review of Economic Studies 71(4), 1001-1026.

[14] Galor, Oded and Joseph Zeira (1993) Income distribution and macroeconomics. Review of Economic Studies 60(1), 35-52.

[15] Kendrick, John W. (1976) The Formation and Stocks of Total Capital. New York: Columbia University Press for the NBER.

[16] Kongsamut, Piyabha, Sergio Rebelo, and Danyang Xie (2001) Beyond balanced growth. Review of Economic Studies 68(4), 869-82.

[17] Laitner, John (2000) Structural change and economic growth. Review of Economic Studies $67(3), 545-61$.

[18] Larson, Donald and Yair Mundlak (1997) On the intersectoral migration of agricultural labor. Economic Development and Cultural Change 45(2), 295-319.

[19] Lewis, Arthur W. (1954) Economic development with unlimited supplies of labour. Manchester School of Economic and Social Studies 22(2), 139-91.

[20] Lloyd-Ellis, Huw and Dan Bernhardt (2000) Enterprise, inequality and economic development. Review of Economic Studies 67(1), 147-68.

[21] Ljungqvist, Lars (1993) Economic underdevelopment: the case of missing market for human capital. Journal of Development Economics 40(2), 219-239. 
[22] Marcouiller, Douglas, Veronica Ruiz de Castilla, and Christopher Woodruff (1997) Formal measures of the informal-sector wage gap in Mexico, El Salvador, and Peru. Economic Development and Cultural Change 45(2), 367-392.

[23] Matsuyama, Kiminori (1992) Agricultural productivity, comparative advantage, and economic growth. Journal of Economic Theory 58(2), 317-34.

[24] Minten, Bart and Steven Kyle (1999) The effect of distance and road quality on food collection, marketing margins, and traders' wages: evidence from the former Zaire. Journal of Development Economics 60(2), 467-495.

[25] Ngai, Rachel and Christopher Pissarides (2004) Structural Change in a Multi-Sector Model of Growth. Mimeo, LSE.

[26] Persson, Torsten and Guido Tabellini (1994) Is inequality harmful for growth? Theory and evidence. American Economic Review 84(3), 600-621.

[27] Psacharopoulos, George (1989) Time trends of the returns to education: cross-national evidence. Economics of Education Review 8(3), 225-33.

[28] Psacharopoulos, George (1994) Returns to investment in education: a global update. World Development 22(9), 1325-43.

[29] Qian, Yingyi (2003) How reform worked in China? In Rodrik, Dani (ed.), In Search of Prosperity: Analytic Narratives on Economic Growth, pp. 297-333. Princeton: Princeton University Press.

[30] Ranis, Gustav and Frances Stewart (1999) V-Goods and the role of the urban informal sector in development. Economic Development and Cultural Change 47(2), 259-288.

[31] Schultz, Paul (1988) Education investments and returns. In Chenery, Hollis and T. N. Srinvasan (eds.), Handbook of Development Economics Volume 1, pp. 543-630. Amsterdam, New York and Oxford: Elsevier Science, North-Holland.

[32] Syrquin, Moshe (1988) Patterns of structural change. In Chenery, Hollis and T. N. Srinvasan (eds.), Handbook of Development Economics Volume 1, pp. 203-273. Amsterdam, New York and Oxford: Elsevier Science, North-Holland.

[33] Tsang, Mun C. (2000) Education and national development in China since 1949: oscillating policies and enduring dilemmas. In Lau, Chung-ming and Jianfa Shen (eds.), China Review 2000, pp. 579-618. Hong Kong: The Chinese University Press. 
[34] Wang, Ping and Danyang Xie (2004) Activation of a modern industry. Journal of Development Economics 73(2), 393-410.

\section{Appendix: Individual and aggregate dynamics of transfers of the model with the sectoral shift of consumption}

\section{A.1 Individual dynamics}

In the unequal opportunity case, i.e. $w_{H}-(1+r) e>w_{L}\left(F_{t}, B_{t}\right)$, transfers of skilled workers are governed by the following equation, which is obtained by substituting $w_{t}^{i}=w_{H}, a_{t}^{i}=b_{t}^{i}-e$, and $H_{t}=F_{t}$ into $(37):$

$$
b_{t+1}^{i}=b_{s}\left(b_{t}^{i} ; F_{t}, B_{t}\right) \equiv\left(1-\gamma_{l}-\gamma_{h}\right)\left\{\left[w_{H}-(1+r) e\right]+(1+r) b_{t}^{i}-P\left(F_{t}, B_{t}\right) \widetilde{c_{L}}\right\},
$$

which depends negatively on $F_{t}$ and aggregate transfers $B_{t}$ through $P_{t}$. The fixed point of the equation for given $P\left(F_{t}, B_{t}\right), b_{s}^{*}\left(F_{t}, B_{t}\right)$, is equal to

$$
b_{s}^{*}\left(F_{t}, B_{t}\right) \equiv \frac{1-\gamma_{l}-\gamma_{h}}{1-\left(1-\gamma_{l}-\gamma_{h}\right)(1+r)}\left\{\left[w_{H}-(1+r) e\right]-P\left(F_{t}, B_{t}\right) \widetilde{c_{L}}\right\}
$$

As for unskilled workers, the dynamics of transfers are governed by the following equation, which is obtained by plugging $w_{t}^{i}=A_{L} P\left(F_{t}, B_{t}\right), a_{t}^{i}=b_{t}^{i}$, and $H_{t}=F_{t}$ into (37):

$$
b_{t+1}^{i}=b_{u}^{i}\left(b_{t}^{i} ; F_{t}, B_{t}\right) \equiv\left(1-\gamma_{l}-\gamma_{h}\right)\left\{(1+r) b_{t}^{i}+\left(A_{L}-\widetilde{c_{L}}\right) P\left(F_{t}, B_{t}\right)\right\}
$$

The dynamic equation for unskilled workers depends positively on $F_{t}$ and $B_{t}$ through $P_{t}$. The fixed point for given $P\left(F_{t}, B_{t}\right), b_{u}^{*}\left(F_{t}, B_{t}\right)$, equals

$$
b_{u}^{*}\left(F_{t}, B_{t}\right) \equiv \frac{1-\gamma_{l}-\gamma_{h}}{1-\left(1-\gamma_{l}-\gamma_{h}\right)(1+r)}\left(A_{L}-\widetilde{c_{L}}\right) P\left(F_{t}, B_{t}\right) .
$$

In the equal opportunity case, i.e. $w_{H}-(1+r) e \leq w_{L}\left(F_{t}, B_{t}\right)$, transfers of the both types of workers follow

$$
b_{t+1}^{i}=b\left(b_{t}^{i}\right) \equiv\left(1-\gamma_{l}-\gamma_{h}\right)\left\{(1+r) b_{t}^{i}+\left[w_{H}-(1+r) e\right]\left(1-\frac{\widetilde{c_{L}}}{A_{L}}\right)\right\}
$$

The equation is obtained from the substitution of $P\left(H_{t}, B_{t}\right)=\left[w_{H}-(1+r) e\right] / A_{L}$ into (42). The fixed point of the equation, $b^{*}$, is

$$
b^{*} \equiv \frac{1-\gamma_{l}-\gamma_{h}}{1-\left(1-\gamma_{l}-\gamma_{h}\right)(1+r)}\left[w_{H}-(1+r) e\right]\left(1-\frac{\widetilde{c_{L}}}{A_{L}}\right) .
$$

The dividing line between the two cases is obtained by substituting $P_{t}=\left[w_{H}-(1+r) e\right] / A_{L}$ 
and $H_{t}=F_{t}$ into $(39)$ and solving the equation for $F_{t}$ :

$$
F_{t}=H^{e}\left(B_{t}\right) \equiv\left(1-\gamma_{l}\right)\left(1-\frac{\widetilde{c_{L}}}{A_{L}}\right)-\frac{\gamma_{l}(1+r) B_{t}}{\left[w_{H}-(1+r) e\right]} .
$$

\section{A.2 Dynamics of aggregate transfers}

In the unequal opportunity case, the dynamics of aggregate transfers $B_{t}$ follow the same equation as the model with $\widetilde{c_{L}}=0$ :

$$
B_{t+1}=B\left(F_{t}, B_{t}\right) \equiv \frac{1-\gamma_{l}-\gamma_{h}}{1-\gamma_{l}}\left\{\left[w_{H}-(1+r) e\right] F_{t}+(1+r) B_{t}\right\} .
$$

The fixed point of the equation for given $F_{t}$ is equal to $B^{*}\left(F_{t}\right) \equiv\left[1-\frac{1-\gamma_{l}-\gamma_{h}}{1-\gamma_{l}}(1+r)\right]^{-1} \times \frac{1-\gamma_{l}-\gamma_{h}}{1-\gamma_{l}}\left[w_{H}-\right.$ $(1+r) e] F_{t}$.

In the equal opportunity case, the dynamics are described by $B_{t+1}=B\left(H^{e}\left(B_{t}\right), B_{t}\right)$, which is obtained by plugging $H_{t}=H^{e}\left(B_{t}\right)$ into $B_{t}=B\left(H_{t}, B_{t}\right)$ :

$$
B_{t+1}=B\left(H^{e}\left(B_{t}\right), B_{t}\right) \equiv\left(1-\gamma_{l}-\gamma_{h}\right)\left\{\left[w_{H}-(1+r) e\right]\left(1-\frac{\widetilde{c_{L}}}{A_{L}}\right)+(1+r) B_{t}\right\}
$$

The fixed point of the equation $B^{* *}$ is given by

$$
B^{* *} \equiv \frac{1-\gamma_{l}-\gamma_{h}}{1-\left(1-\gamma_{l}-\gamma_{h}\right)(1+r)}\left[w_{H}-(1+r) e\right]\left(1-\frac{\widetilde{c_{L}}}{A_{L}}\right),
$$

which is equal to $b^{*}$. The number of skilled workers at $B^{* *}, H^{* *} \equiv H\left(B^{* *}\right)$, is

$$
H^{* *} \equiv H\left(B^{* *}\right)=\left[1-\frac{\gamma_{l}}{1-\left(1-\gamma_{L}-\gamma_{h}\right)(1+r)}\right]\left(1-\frac{\widetilde{c_{L}}}{A_{L}}\right) .
$$

